\title{
Assessment of potential strong ground motions in the city of Rome
}

\author{
Antonio Rovelli, Arrigo Caserta, Luca Malagnini and Fabrizio Marra \\ Istituto Nazionale di Geofisica, Roma, Italy
}

\begin{abstract}
A methodology is used which combines stochastic generation of random series with a finite-difference technique to estimate the expected horizontal ground motion for the city of Rome as induced by a large earthquake in the Central Apennines. In this approach, source properties and long-path propagation are modelled through observed spectra of ground motion in the region, while the effects of the near-surface geology in the city are simulated by means of a finite-difference technique applied to 2-D models including elastic and anelastic properties of geologic materials and topographic variations. The parameters commonly used for earthquake engineering purposes are estimated from the simulated time histories of horizontal ground motion. We focus our attention on peak ground acceleration and velocity, and on the integral of the squared acceleration and velocity (that are proportional to the Arias intensity and seismic energy flux, respectively). Response spectra are analyzed as well. Parameter variations along 2-D profiles visualize the effects of the small-scale geological heterogeneities and topography irregularities on ground motion in the case of a strong earthquake. Interestingly, the largest amplification of peak ground acceleration and Arias intensity does not necessarily occur at the same sites where peak ground velocity and flux of seismic energy reach their highest values, depending on the frequency band of amplification. A magnitude 7 earthquake at a distance of $100 \mathrm{~km}$ results in peak ground accelerations ranging from 30 to 70 gals while peak ground velocities are estimated to vary from 5 to $7 \mathrm{~cm} / \mathrm{s}$; moreover, simulated time histories of horizontal ground motion yield amplitudes of $5 \%$ damped pseudovelocity response spectra as large as $15-20 \mathrm{~cm} / \mathrm{s}$ for frequencies from 1 to $3 \mathrm{~Hz}$. In this frequency band, the mean value is $7 \mathrm{~cm} / \mathrm{s}$ for firm sites and ranges from 10 to $13 \mathrm{~cm} / \mathrm{s}$ for soil sites. All these results are in good agreement with predictions based on regressions of Italian and Western North American data.
\end{abstract}

Key words strong motions - stochastic simulations - site effects - finite-difference method - 2-D modelling

\section{Introduction}

The city of Rome is known for its large concentration of monuments and ancient buildings, many of which have assumed political and strategical relevance. Because of their extreme vulnerability, the evaluation of the characteristics of the strongest expected ground shaking for specific areas of the city is a basic tool for high-priority actions aimed at mitigating the seismic risk.
Unfortunately, no strong-motion recordings are available for the city of Rome, which makes it impossible to make any estimate based on actual measurements of ground motion induced by earthquakes. The selection of a suitable approach for estimating the seismic input to the city is therefore of great importance. We decided to follow what, at least preliminarily, seemed to be the most obvious approach: to use local and regional strong-motion data to evaluate the ground motion parameters as a function of the characteristics of seismic source and regional propagation. In practice, we proceeded through the following steps:

1) identification of the seismogenic areas that are most relevant for the city of Rome, and 
estimation of the largest expected earthquake for each of them;

2) use of strong-motion data recorded in these areas to construct a spectral model in terms of source scaling and spectral attenuation laws;

3) use of stochastic procedures to generate a set of synthetic seismograms with the purpose of characterizing the seismic input to the rigid basement (bedrock) of the city;

4) calculation of transfer functions for different geological and geomorphological settings, and their convolution with the synthetic accelerograms at the bedrock;

5) using the synthetics obtained for the city's surface, the expected parameters of engineering significance are finally estimated, among which peak ground velocity and acceleration, Arias intensity, duration, flux of the seismic energy, response spectra.

\section{Seismogenic areas of interest for the city of Rome}

Molin and Guidoboni (1989) first performed an accurate revision of the historical sources concerning the earthquakes felt in Rome. Table I lists the most important earthquakes that were felt by the city of Rome during its long history. Epicentral intensity $\left(I_{0}\right)$ and intensity estimated for the city $\left(I_{R}\right)$ are given in the Mercalli-Cancani-Sieberg scale. This summary shows that the destructive earthquakes that may affect Rome occur mainly within two distinct seismogenic districts: the Alban Hills region, located approximately $25 \mathrm{~km}$ from the centre of Rome, and the Central Apennines, located in a distance range 80-170 km from Rome. Figure 1 shows the epicentral location of earthquakes reported by the catalogue.

The Alban Hills were the object of several detailed investigations, concerning both the characteristics of the local seismicity (Amato et al., 1994; Chiarabba et al., 1994) and its recurrence and magnitude pattern (Basili et al., 1987). From an analysis of more than 1100 shocks recorded in the period from April 1990 to March 1991 (Amato et al., 1994), it emerged that the earthquakes are mostly concentrated in an area that is also characterized by the most recent volcanic activity ( $0.3 \mathrm{Ma}$ or younger) and that extends nearly up to the southeastern suburbs of Rome. A second area that is characterized by more sporadic activity was detected

Table I. Major local and regional earthquakes felt by the city of Rome (redrawn from Molin and Guidoboni, 1989).

\begin{tabular}{cccc}
\hline \hline Data & $I_{0}$ & $I_{R}$ & Origin Area \\
\hline 83 b.C. & - & - & Unknown \\
$72-70$ b.C. & - & - & Unknown \\
51 & - & - & Unknown \\
443 & - & - & Unknown \\
484 or 508 & - & - & Unknown \\
801 & - & VII-VIII & Central Apennines \\
1349 & X & VII-VIII & Central Apennines (L'Aquila) \\
1703 & X & VI-VII & Central Apennines (Val Nerina) \\
1703 & X & VII & Central Apennines (L'Aquila) \\
1812 & VII & VII & Rome \\
1899 & VII-VIII & VI & Albani Hills \\
1915 & XI & VI-VII & Central Apennines (Fucino) \\
\hline
\end{tabular}




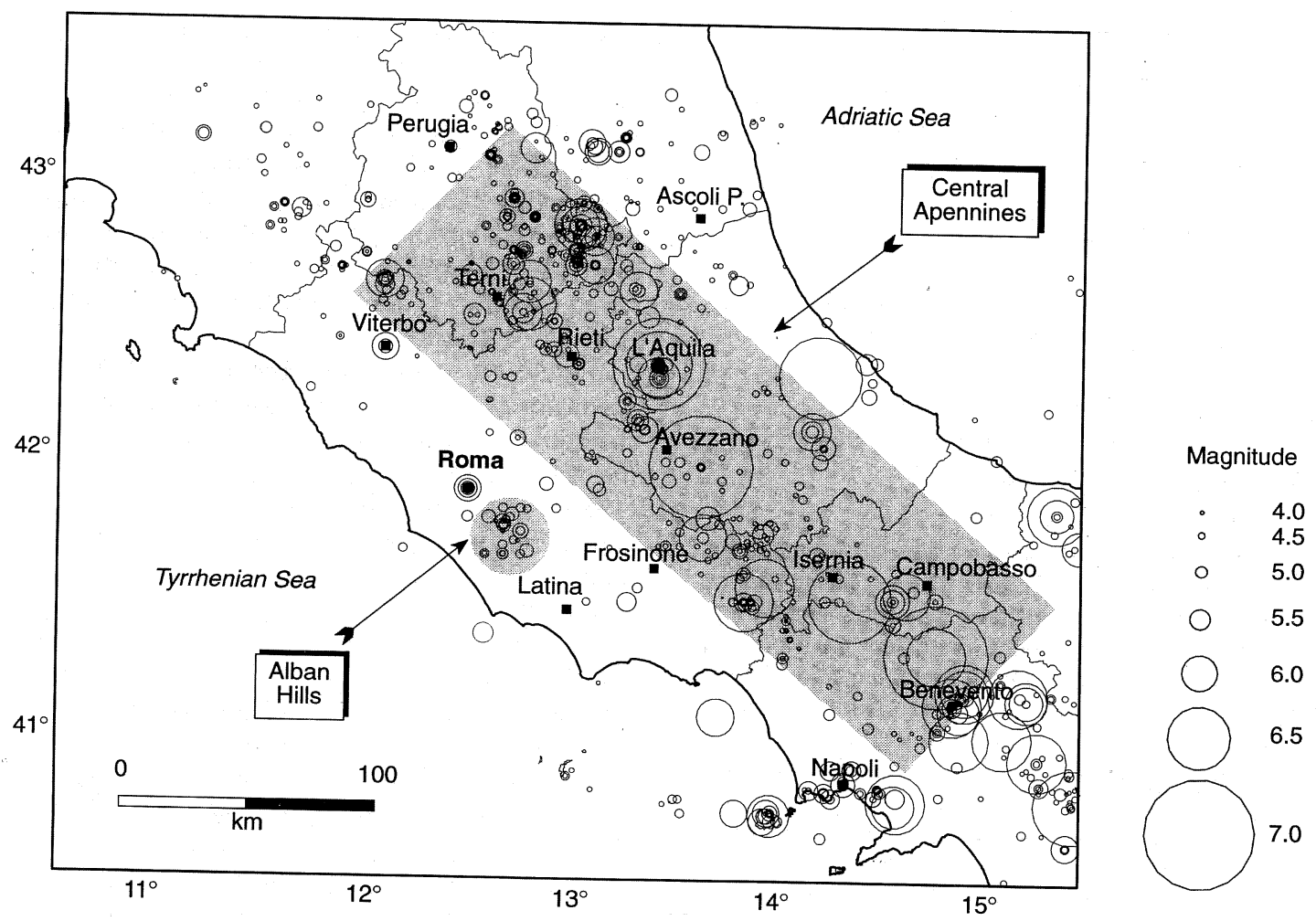

Fig. 1. Earthquakes of the Italian catalogue. Two main seismotectonic districts emerge as source of the earthquakes felt in Rome with intensity of VI or higher: the Alban Hills, at an average distance of $25 \mathrm{~km}$ from Rome, and Central Apennines, at distances ranging from 80 to $170 \mathrm{~km}$.

in the northern part of the Alban Hills volcanic complex, east of Rome and not far from its suburbs (Amato et al., 1994). The hypocentral depth is typically in the range 3 to $6 \mathrm{~km}$. In a study on the sequence of the events based on the statistics of the extreme values, Basili et al. (1987) found that the maximum expected magnitude for an earthquake occurring in the Alban Hills is 5.2. The trend of the macroseismic field for events of this seismogenic district suggests a strong attenuation of the effects, most likely explained by their shallow hypocentral depth. A few available strong-motion recordings suggest that these earthquakes show spectra of the seismic radiation which are compatible with a source omega-square model with a Brune stress drop of about 20 bar. For an extreme event of magnitude $\approx 5$ occurring at a distance of $25 \mathrm{~km}$, this source model yields the spectral shape shown in fig. 2, curve (b).

The seismogenic structures of the Apennines are characterized by fault length usually in the range of $10-20 \mathrm{~km}$ and exhibit prevalent normal faulting focal mechanisms (see for example Valensise et al., 1993 and 1994). The hypocentral depth is generally in the range of $10-15 \mathrm{~km}$. The historical record and the available instrumental data suggest that the maximum expected magnitude for earthquakes generated within this seismogenic area is about 7 (see fig. 1). The occurrence of earthquakes of this size at a distance of about $100 \mathrm{~km}$ from Rome is now testified also by the results of paleoseismological investigations (e.g. Serva 


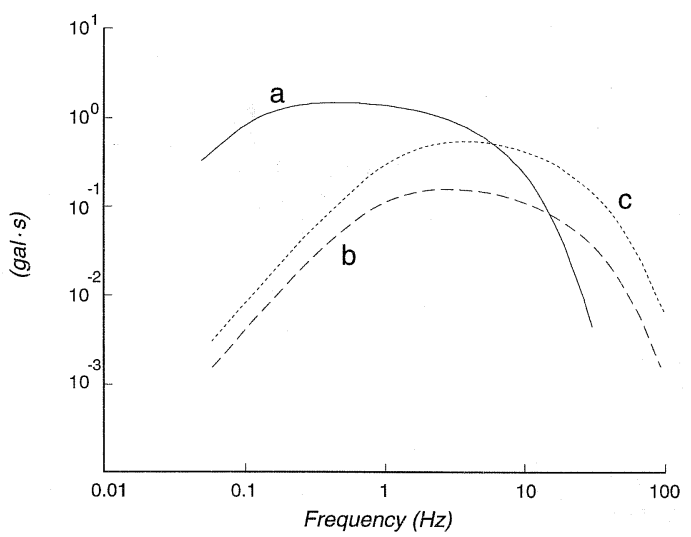

Fig. 2. Spectra of horizontal ground acceleration based on theoretical models fitting strong-motion data recorded in Central Italy. The three curves represent: spectral amplitudes predicted for Rome as effect of (a) a magnitude 7 earthquake in Central Apennines at a distance of $100 \mathrm{~km}$ (omega squared model with a Brune stress drop of 100 bars), (b) a magnitude 5 earthquake in the Alban Hills at a distance of $25 \mathrm{~km}$ (omega squared model with a Brune stress drop of 20 bars), and (c) a magnitude 5 earthquake in the Alban Hills at a distance of $12.5 \mathrm{~km}$ (omega squared model with a Brune stress drop of 100 bars).

et al., 1986; Brunamonte et al., 1991; Pantosti et al., 1992). These investigators stress the existence of geological evidence for many large surface-faulting events in the Central Apennines, which in itself testifies the large magnitude of earthquakes in this region.

The definition of the spectral model for the largest earthquakes of Central Apennines was the object of various investigations (Rovelli et al., 1988; Cocco and Rovelli, 1989). Based on strong-motion recordings written by stations of the national accelerometric network run by the Italian Electric Power Agency (ENEL), these authors estimated a spectral model for the most recent large earthquakes of the Central and Central-Southern Apennines as the combination of two different contributions: a source term (characterized by an omega-square spectrum whose scaling law as a function of moment-magnitude is controlled by the regional value of the stress drop), and a propagation term, which includes both geometrical spreading and scattering and anelastic attenuation. With the exception of a few stations clearly influenced by local site conditions, this model appeared well suited for describing the average trend of the ground motion spectra as a function of the moment-magnitude (within the range $4<M<7$ ) and of the epicentral distance (for $R<120 \mathrm{~km}$ ).

Figure 2, curve (a) shows the expected spectrum for «firm sites» for a magnitude 7 earthquake at a distance of $100 \mathrm{~km}$, based on the spectral model proposed by Rovelli et al. (1988). The comparison of the two spectra (a) and (b) in fig. 2 shows that the spectral amplitudes of the largest expected earthquake generated in the Alban Hills at a distance of $25 \mathrm{~km}$ are always lower than the expected spectrum for the Central Apennines throughout all the considered range of frequencies. The stress drop of Alban Hills earthquakes must be increased from 20 to 100 bar and the epicentral distance reduced from 25 to $12.5 \mathrm{~km}$ (curve (c) in fig. 2) to generate high frequency motions $(f>5 \mathrm{~Hz})$ with amplitudes comparable to those produced by magnitude 7 earthquakes at $100 \mathrm{~km}$ distance. Nevertheless the spectrum of earthquakes in the Apennines is always substantially more energetic in the frequency band of engineering significance $(0.5<f<5 \mathrm{~Hz})$.

Based on this reasoning, we assume in this paper that the event that could have the largest destructive potential is a magnitude 7 earthquake located in the Apennines, at a distance of $100 \mathrm{~km}$ from Rome. This paper aims to numerically simulate ground motion produced in the city by such an earthquake.

\section{Evaluating the seismic input in the urban area of Rome: an approach for the com- putation of the parameters of engineering significance}

Following the largest earthquakes of the past few years in the world, strong-motion data have been collected in densely urbanized areas which showed extreme diversification of the damage within short distances. The analysis of 
these data showed that variations in the nearsurface geology had produced phenomena of amplification of the ground motion which were locally responsible for the most severe damage (for example in Mexico City, see Singh et al., 1988, or in Santa Cruz, California, see Cranswick et al., 1990). Similar effects might occur also in the city of Rome, where shallow geologic heterogeneities and the existence of large deposits of recent unconsolidated sediments overlying a bedrock of Pliocene consolidated clays may create favourable conditions for amplification effects (see Salvi et al., 1991). A direct confirmation of the above is offered by the analysis of the damage produced by the January 13, 1915, Fucino earthquake (Ambrosini et al., 1987). This earthquake was felt in Rome with macroseismic intensity up to VII MCS (Mercalli-Cancani-Sieberg) and was indeed the last of the large events to have struck the city in its history. Traces of the earthquake damage can only be found in what is now Rome's Historical Centre, but only because in 1915 the urbanized area did not extend much further than that. To what is left of the old city we should now add a much larger and just as vulnerable urbanized area.

The near-surface geology of Rome is characterized by the existence of an intricate hydrographic network that incised very deeply the underlying rocks during the last glacial phase (Würm). During the subsequent rise of sea level these deeper valleys were backfilled with alluvial Holocene deposits essentially consisting of unconsolidated clayey-sandy sediments (Feroci et al., 1990). This was but the last of a series of sedimentary cycles associated with the glacio-eustatic changes that characterized the continental sedimentation in the area of Rome starting in the Middle Pleistocene $(0.88 \mathrm{Ma})$. The normal sedimentary processes were followed by the emplacement of a large volume of pyroclastic deposits produced during the activity of the Sabatino and Albano volcanic districts that started around $0.6 \mathrm{Ma}$ (Cioni et al., 1993). The paleogeographic evolution of the Roman area was finally influenced by intense tectonic activity due to concurrent structural elements that make this area rather unique within the geodynamic context of the Italian peninsula. The combination of these elements has created an extremely diverse geological setting (see fig. 3). In addition, traditional geologic investigations are hampered by the intense urbanization of the area. A more detailed reconstruction of the geologic setting of this area has only recently been achieved thanks to the creation of a data bank that includes over 3000 stratigraphies from wells drilled for various purposes over the past decades. The analysis and comparison of these data has led to a substantial revision of the stratigraphy of the area as it was known in literature and has improved the knowledge of the near-surface characteristics of the Roman area (Carboni et al., 1991; Feroci et al., 1990, Funiciello et al., 1992; Marra, 1994; Marra et al., 1994a,b).

The seismic response of the urban area of Rome is influenced by the alternation of recent unconsolidated deposits with more rigid lithologies. To calculate the ground motion to be produced by an earthquake we, therefore, found it necessary to develop a method which would take into consideration the details of the geologic setting of the area.

Our first step was to make a statistical determination of the seismic input at the bedrock for the largest possible event. Using a 2-D modelling we then calculated the transfer function of some different stratigraphic configurations that characterize the surface geology of the city. This was done by calculating the SHresponse to a delta-like input along 2-D sections selected as the most representative of the various structural settings of Rome. Finally, through a convolution we could simulate the transverse component of the horizontal ground motion expected at the surface for the given event.

The following sections 3.1., 3.2. and 3.3. describe the procedure in detail.

\subsection{Characterization of the seismic input to the bedrock by generation of random series}

Two different approaches may be followed to synthetize a seismic input: deterministic or stochastic. In the deterministic approach the 

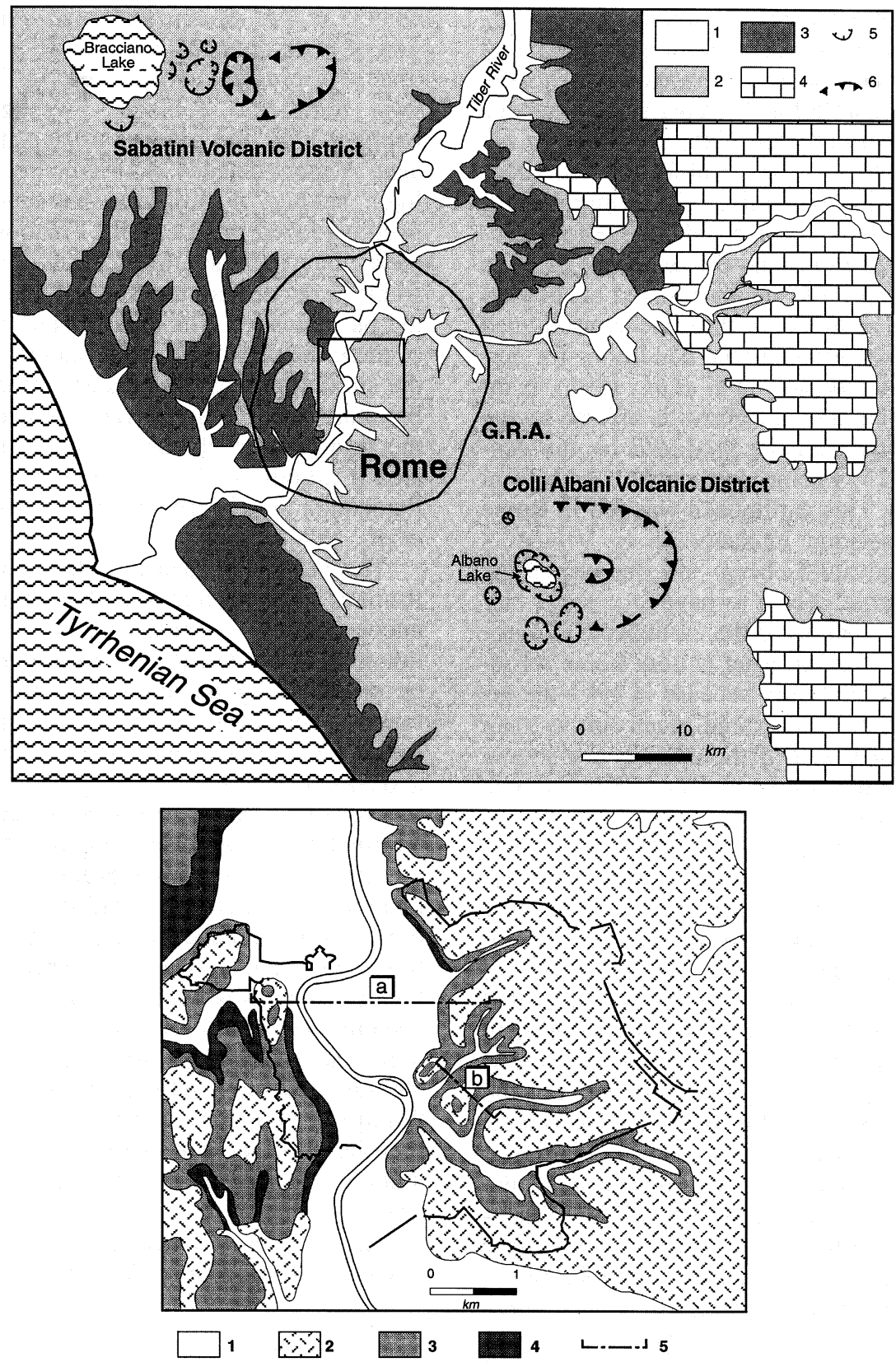

Fig. 3. On the top: geological scheme of the area of Rome. 1) Recent alluvium; 2) volcanics; 3) Plio-Pleistocene sedimentary deposits; 4) Meso-Cenozoic carbonate units; 5) craters; 6) caldera ryms. G.R.A. is the freeway belt surrounding Rome. At the bottom: details relative to the historical centre. 1) Recent alluvium; 2) volcanics; 3) Middle Pleistocene continental deposits; 4) Pliocene clays (bedrock); 5 (a and b) tracks of the profiles shown in fig. 5. 
most common procedure consists in representing the source by means of a double couple mechanism and propagating the seismic waves through a model of the lithosphere which is usually schematized as a series of parallel flat layers. These models can be extremely useful to understand peculiar aspects of the phenomenon that is to be numerically simulated when the long-path propagation medium is regularly layered and source mechanisms are well known.

A similar method has recently been applied to the city of Rome by Fäh et al. (1993), who used the mode summation technique with a 2-D scheme of layered lithosphere to simulate the incoming wavefield to the bedrock of Rome generated by a $M_{L}=6.8$ earthquake, roughly $85 \mathrm{~km}$ east of the city. It should be noted, however, that due to the large number of parameters that need to be set a priori (the three angles that define the fault geometry, the hypocentral depth, and the velocity, density, and quality factor of tens of layers through which the seismic radiation is propagated in the upper crust), the deterministic method is rather unsuitable for engineering purposes. Indeed, many of the model parameters are poorly constrained. Others are highly undependable: for example the excitation of the highest frequency waves varies significantly as a function of the hypocentral depth when using pointsource models. Furthermore, the assumption of wave propagation through flat parallel layers and the lack of small-scale heterogeneities in modelling both the point source and the propagation produce very peculiar results that may not agree with the trend of the observed data. For instance, the postcritical reflection at 60 $\mathrm{km}$ postulated by the approach followed by Fäh et al. (1993) neither emerges from the observed instrumental data (see Sabetta and Pugliese, 1987) nor affects macroseismic intensities, at least up to $150 \mathrm{~km}$ (Diego Molin, private communication). In that modelling, such postcritical reflection was emphasized by a regional propagation through flat parallel layers in the crust that is hardly suitable in the case of a highly heterogeneous region. Indeed, the city of Rome is located close to a NS-trending lithospheric discontinuity marked at the surface by a well known series of transtensional-right lateral lineaments following an en echelon geometry. These lineaments identify a shear-zone extending from the Sabina region of the Central Apennines (Faglia di Cottanello, see Alfonsi et al., 1991), to the city of Rome, along the NS section of the Tiber River valley (Faccenna and Funiciello, 1994; Marra et al., 1994a). Another series of similar structures is located further to the east between the area of Bagni Albule (Tivoli) and the Alban Hills (Faccenna and Funiciello, 1993). In addition, this discontinuity marks the boundary between areas that are characterized by highly different values of the thermal flow. This implies that the elastic and anelastic parameters should be allowed to vary significantly along the path from the source to the bedrock of Rome when performing deterministic modelling. Finally this discontinuity also marks the boundary between two sectors of the crust having substantially different thickness. Available reconstructions of the Moho trend (Wigger, 1984) show a difference in thickness of approximately ten kilometers between the Fucino area and the area of Rome, a fact that directly rules out the use of models that describe the regional propagation with simple geometries.

We therefore believe that a stochastic approach is by far to be preferred for engineering purposes. It does not require the knowledge of the details of source geometry and lithosphere structure, and is well suited to reproduce the stochastic nature of the high-frequency ground motion. The main advantages in modelling the seismic radiation are:

1) it needs a very low number (three to four) of parameters, a fundamental requirement of any prediction method. The use of models based on hundreds of parameters not constrained by direct measurements can thus be avoided;

2) it allows one to produce a large number of realizations of synthetic seismograms in short computation times, subsequently calculating averages that drastically reduce the statistical uncertainties on those parameters that are most significant from an engineering point of view (peak values of the ground motion, dura- 
tion, Arias intensity, seismic energy, response spectra). Furthermore, limited variations of the few parameters of the stochastic model allow us to evaluate how sensitive the results are to variations in these parameters, and the statistic fluctuations of the results can then be interpreted and evaluated on a physical basis depending on the uncertainty associated with the model parameters;

3) it makes it easy to model the amplitude of high frequencies of ground motion (up to $20 \mathrm{~Hz}$, and even more), something which can not be done with deterministic models both because of physical limitations (for frequencies of over $f \approx 1 \mathrm{~Hz}$ the seismic radiation is controlled by the irregularities of the rupture process and by the heterogeneities along the propagation path, two factors that are missing altogether in deterministic models) and because they require too long computing times. On the contrary, a stochastic modelling is well suited to reproduce an incoherent sequence of random phases.

We therefore adopted a stochastic approach that was restricted to use and to reproduce the only data that were really available from observations: the trends of the spectra of the regional ground motion. The starting point of our approach is to determine the spectra of the expected motion at the city's bedrock for the largest possible earthquake. Since the estimation of the above-mentioned engineering parameters requires a reconstruction of the time history of ground motion, we used a method that supplies a series of synthetic accelerograms, all of which are consistent with the expected spectrum which is estimated using the available strong-motion data.

In our approach the spectrum $A_{B}(\omega, R)$ of the horizontal acceleration at the bedrock is calculated as:

$A_{B}(\omega, R)=\frac{A_{F S}(\omega, R)}{2}=\frac{S_{0}(\omega) \cdot D(\omega, R) \cdot P(\omega)}{2}$

where $A_{F S}(\omega, R)$ is the spectrum of the motion expected at distance $R$ for a firm site without topographic irregularities. The factor 2 compensates for the free surface effect since $A_{B}(\omega, R)$ refers to the input at the bedrock. $S_{0}(\omega)$ is the source spectrum, expressed using an omega-square model with a constant Brune stress drop (Rovelli et al., 1988). The term describing the propagation, $D(\omega, R)$, can be expressed as follows

$$
D(\omega, R)=\frac{\exp \left(-\frac{\omega \kappa}{2}\right) \exp \left(-\frac{\pi R}{\beta_{S} Q_{0}}\right)}{R}
$$

where $\beta_{S}$ is the mean value of the shear-wave velocity in the lithosphere $\left(\beta_{S}=3.2 \mathrm{~km} / \mathrm{s}\right)$, and $\kappa$ and $Q_{0}$ are two attenuation parameters estimated from the accelerometric data available for the Central and Central-Southern Apennines (equal to $0.064 \mathrm{~s}$ and $100 \mathrm{~s}$, respectively, see Rovelli et al., 1988). The value $\kappa=0.064 \mathrm{~s}$ has been adopted being the average value resulting from data of the Apennine region. Notice that this value is suitable to an intermediate-velocity bedrock $\left(\beta_{B}=600 \mathrm{~m} / \mathrm{s}\right)$, at an epicentral distance $R=100 \mathrm{~km}$ (see also Anderson and Hough, 1984). Based on Cocco and Rovelli (1989), the Brune stress drop $(\Delta \sigma)$ was set equal to 100 bars. In (3.1), $P(\omega)$ describes the amplification effect for different wavelengths resulting from the variation of the seismic impedance in the propagation from the crystalline basement to the top of the bedrock. Following Joyner and Fumal (1984) and Boore (1986), $P(\omega)$ was represented by a frequency function (table II). The high-frequency asymptotic value of $P(\omega)$ is controlled by the impedance contrast

$$
P_{0}=\sqrt{\frac{\rho_{S} \beta_{S}}{\rho_{B} \beta_{B}}},
$$

where $\rho_{S}$ and $\beta_{S}$ indicate the density of the medium $\left(2.7 \mathrm{~g} / \mathrm{cm}^{3}\right)$ and the velocity of the shear waves in the focal region $(3.2 \mathrm{~km} / \mathrm{s})$, respectively, and $\rho_{B}$ and $\beta_{B}$ the same quantities at the top of the bedrock $\left(2.1 \mathrm{~g} / \mathrm{cm}^{3}\right.$ and $0.6 \mathrm{~km} / \mathrm{s}$, respectively). The trend of $P(\omega)$ at low fre- 
Table II. Crustal amplification from the crystalline basement to the top of bedrock beneath Rome.

\begin{tabular}{cc}
\hline \hline Log frequency & Log amplification factor \\
\hline-1 & 0.01 \\
-0.7 & 0.15 \\
-0.3 & 0.38 \\
0.0 & 0.42 \\
1 & 0.42 \\
\hline
\end{tabular}

quency is controlled by the fact that longer wavelengths are less sensitive to impedance changes in the upper crust. For $\omega$ approaching zero

$$
P(0)=1 \text {. }
$$

In the case of the city of Rome, $P(\omega)$ has been modelled assuming a total thickness of about $8 \mathrm{~km}$ (Cosentino and Parotto, 1992) between the top of the crystalline basement and the top of the Pliocene complex. Under these conditions we obtain $P_{0}=2.6$ with a cutoff frequency of $0.3 \mathrm{~Hz}$, roughly. Values of $P(\omega)$ for several frequencies are listed in table II: for the other frequencies a linear interpolation was used.

Once the spectrum of the expected horizontal acceleration at the bedrock has been determined using (3.1), it is necessary to apply a procedure for the generation of a sequence of time series, which statistically represent different realizations of the same spectral process. Among several others, the technique proposed by Boore (1983) is the most used in seismological modelling for engineering purposes. This technique is based on the generation of limited bandwidth Gaussian white noise which is constrained to have a finite duration by means of a suitable time window, the envelope of which controls the trend of the amplitudes as a function of time. The mean value of the windowed time series is zero, and the variance is chosen to give an average spectral amplitude equal to 1 . The spectrum of the windowed time series is multiplied by the expected acceleration spectrum (3.1), and Fourier back transforma- tion to the time domain provides an acceleration time history depending on the seed used for generating the random series (details can be found in Boore, 1983). To obtain more realizations of the same process, new random series must be generated each time changing the sequence's seed. This procedure allows an unlimited number of synthetic accelerograms to be obtained, the spectral content of which will be as similar as possible to that imposed a priori based on the data contained in the records available at regional scale. For the algorithm used see Di Bona and Rovelli (1990).

If multiplied by a factor of 2 to account for the free surface effects, these accelerograms become representative of the ground motion for outcrops of the Pliocene bedrock within the urban area, and as these are the firmest sites of the city they also represent the lowest expectable level of ground shaking. Figure $4 \mathrm{a}$ shows an example of individual expected ground acceleration and velocity obtained applying this approach for a moment-magnitude of 7 and a distance from the fault equal to $100 \mathrm{~km}$. By averaging over the ensemble of several realizations the differences will soon disappear: 25 simulations are enough to contain the standard deviation of the average peak value within $16 \%$ for acceleration and within $25 \%$ for velocity.

If we assume a log-normal distribution of the peak values, the average operation over the ensemble of 25 realizations yields for firm sites in the city

$$
\begin{aligned}
& <\log a_{P}>=1.48 \pm 0.06 \\
& <\log v_{P}>=0.68 \pm 0.11
\end{aligned}
$$

where $a_{P}$ and $v_{P}$ are peak ground acceleration and velocity, respectively. After calculating the antilogarithm of (3.2) we obtain $a_{P}=30$ gal and $v_{P}=5 \mathrm{~cm} / \mathrm{s}$. These mean values agree satisfactorily with peak ground acceleration and velocity (37 gals and $3 \mathrm{~cm}$, respectively) obtained for firm sites from the fit of Italian strong-motion data, with $M=7$ and $R=100$ $\mathrm{km}$ (Sabetta and Pugliese, 1987). Figure 4b also shows the $5 \%$ damped pseudovelocity response spectrum for firm sites as obtained by 

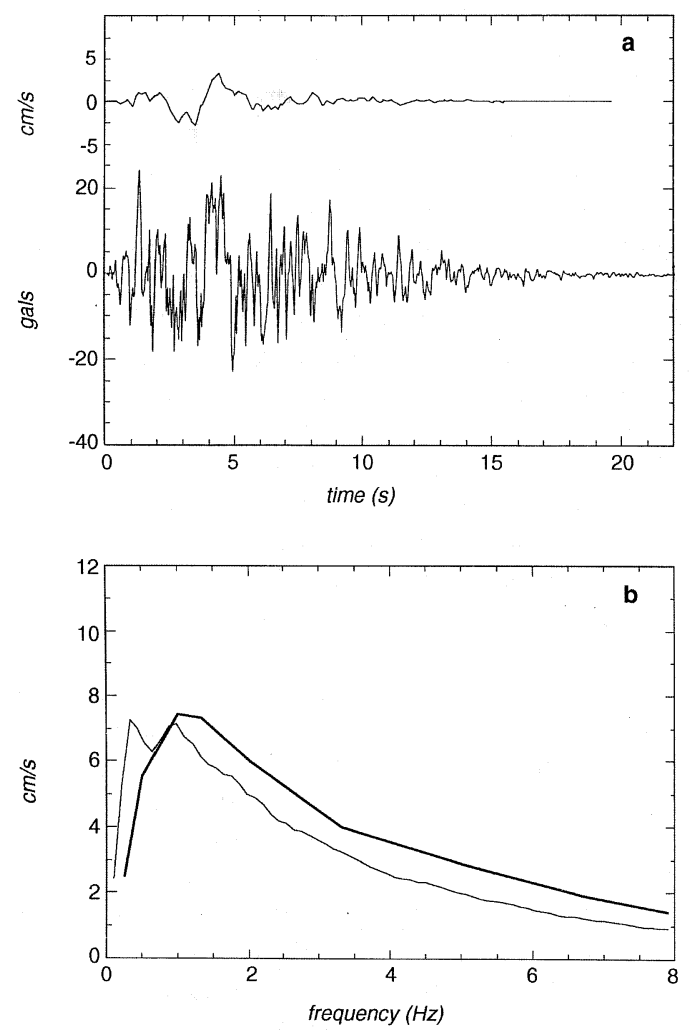

Fig. 4a,b. a) An example of time histories of horizontal ground acceleration and velocity simulated for firm sites in Rome, as induced by a magnitude 7 earthquake at a distance of $100 \mathrm{~km}$; b) $5 \%$ damped pseudovelocity response spectra expected for firm sites, averaged over an ensemble of 25 simulations. The overimposed solid line represents the prediction by Pugliese and Sabetta (1989) using the Italian strong-motion data set.

averaging the response spectra of the 25 simulations. Again, the comparison with the $\mathrm{Pu}-$ gliese and Sabetta (1989) regression based on observed data shows a satisfactory agreement.

Notice that the interval of 1 s.d. in (3.2) refers to the average of the 25 simulations. This statistical uncertainty is merely mathematical and has no physical bearing as it descends from the use of a stochastic method. To evaluate to what extent the simulation results are sensitive to variations of the model's physical parameters $\left(\Delta \sigma, \kappa\right.$ and $\left.Q_{0}\right)$, we determined the extreme variation corresponding to a $10 \%$, $20 \%$ and $30 \%$ concomitant fluctuation of these parameters. Table III shows the values of $a_{P}$ and $v_{P}$ corresponding to these percentage variations of the model parameters. It can be noted that $a_{P}$ and $v_{P}$ can vary up to a factor of 2 in the most unfavourable case of the parameter variation shown in table III.

\subsection{2-D modelling of the seismic response to a delta-like input incident to the bedrock}

The geological setting of the subsurface is fairly complex in the area of Rome. In particular, the surfaces that mark the boundaries between the different lithological units are extremely irregular since they almost always coincide with topographic paleosurfaces that underwent intense erosion and often also tectonic dislocation. In some instances the lithological composition of the different units varies considerably giving rise to significant lateral and vertical variations. Having to deal with such heterogeneities, and in order to account for as many as possible different structural settings and sizes of sedimentary bodies, we were forced to select some characteristic profiles mostly representative of the geology and geomorphology of the city. The main element is represented by the Holocene deposits filling the Tiber river valley, a 1 to $2 \mathrm{~km}$-wide and 70 m-deep geologic feature NS crossing fairly regularly the city of Rome. A large part of the Historical Centre can be satisfactorily described by such a 2-D model (see fig. 5, on the left). It has been already object of previous investigations (Boschi et al., 1994), where the effects of the near-surface geology on ground motion were evaluated by means of a 2-D numerical modelling. Compared with that paper, in this modelling some values of elastic and anelastic parameters have been revisited (see table IV). Preliminary results of recent crossand down-hole measurements in downtown Rome (a cooperation between Istituto Nazionale di Geofisica and the University of Rome «La Sapienza») suggest values of shear-wave 
Table III. Variations of $a_{P}$ and $v_{P}$ as a function of percent fluctuations of the model parameters.

\begin{tabular}{|c|c|c|c|}
\hline & & $a_{P}$ & $v_{P}$ \\
\hline$+10 \%$ & $\begin{array}{l}\kappa=0.058 \\
\Delta \sigma=110 \\
Q_{0}=110\end{array}$ & 37 & 5 \\
\hline$-10 \%$ & $\begin{array}{l}\kappa=0.070 \\
\Delta \sigma=90 \\
Q_{0}=90\end{array}$ & 23 & 4 \\
\hline$+20 \%$ & $\begin{array}{l}\kappa=0.051 \\
\Delta \sigma=120 \\
Q_{0}=120\end{array}$ & 47 & 6 \\
\hline$-20 \%$ & $\begin{array}{l}\kappa=0.077 \\
\Delta \sigma=80 \\
Q_{0}=80\end{array}$ & 17 & 3 \\
\hline$+30 \%$ & $\begin{array}{l}\kappa=0.045 \\
\Delta \sigma=130 \\
Q_{0}=130\end{array}$ & 58 & 7 \\
\hline$-30 \%$ & $\begin{array}{l}\kappa=0.083 \\
\Delta \sigma=70 \\
Q_{0}=70\end{array}$ & 12 & 2 \\
\hline
\end{tabular}

velocity which are significantly lower than those used so far to model the seismic response in the city of Rome (Fäh et al., 1993; Boschi et al., 1994). This is particularly true for the bedrock Pliocene clays, whose shear-velocity ranges from 450 to $550 \mathrm{~m} / \mathrm{s}$ in ten metres below the bedrock-alluvium interface. In our modelling, a value as low as $600 \mathrm{~m} / \mathrm{s}$ has been used for the stiff basement against the values of $1.3-1.5 \mathrm{~km} / \mathrm{s}$ used by Fäh et al. (1993) and 1 $\mathrm{km} / \mathrm{s}$ used by Boschi et al. (1994). Moreover, recent estimates of the quality factor in upper sediment layers both in Italy (Malagnini et al., 1994) and worldwide (Jongmans and Campillo, 1993; Gibbs et al., 1994) suggest that a $Q$ value of 10 is extremely realistic for the Quaternary alluvium, and even lower values for soft unconsolidated deposits. Table IV lists the values of elastic and anelastic parameters used for the different types of geologic materials.

A second structural situation recurrent in Rome has been object of investigation in this paper (fig. 5, on the right): close smaller-size incisions (width and depth in the order of hun- dred metres and some tens of metres, respectively) as a part of complex profiles in which the close incisions are filled up by unconsolidated sediments that result in an extended element of surface continuity. As a consequence, these surficial soft-sediment bodies assume extremely variable thickness. The curvature variations of their upper and lower surface create a situation extremely favourable to significant focusing and defocusing effects, and closely neighboring sites can be characterized by large differences in ground motion.

To simulate the propagation in the upper layers, we computed the seismic response to a transient delta-like input supplied as a polarized plane $S H$-wave vertically or obliquely incident to the bedrock of the selected profiles. We used a finite-difference numerical technique (Mitchell and Griffith, 1980). Dissipation was introduced in the calculations following the technique proposed by Emmerich and Korn (1987), which is based on the rheological properties of the generalized Maxwell body. The velocity and $Q$ models were constructed by digitizing the boundaries between the different units on the 2-D geological profiles.

The restriction to 2-D modelling and pure $\mathrm{SH}$ waves significantly simplifies the reality. It should be noted, however, that profiles (a) and (b) (see fig. 3) are oriented EW and NW-SE, respectively. Using the 1915, Fucino earthquake (generated by a $70^{\circ}$ dipping, NW-SE trending fault located $90 \mathrm{~km}$ east of Rome) as a reference strong event affecting Rome, we find a different $S H$ theoretical polarization depending on the source mechanism. In particular, it varies from NS for a pure normal faulting (as suggested by Ward and Valensise, 1989) to NE-SW for normal faulting with leftlateral strike component (Galadini et al., 1991). This means that, in practice, both the profiles are illuminated by $S$ waves characterized by a significant out-of-plane component.

The input at the bedrock was described analytically by means of a Gabor function $g(t)$ such as

$$
g(t)=\exp \left[-\left(\omega_{P}\left(t-t_{S}\right) / \gamma\right)^{2}\right] \cos \left[\omega_{P}\left(t-t_{S}\right)+\psi\right]
$$


Tiber Valley
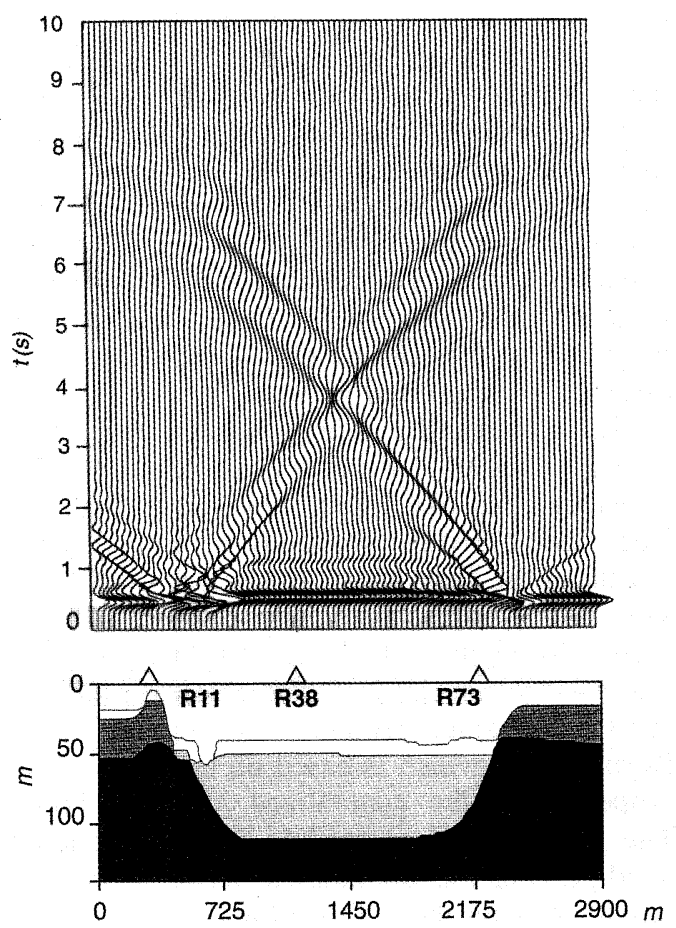

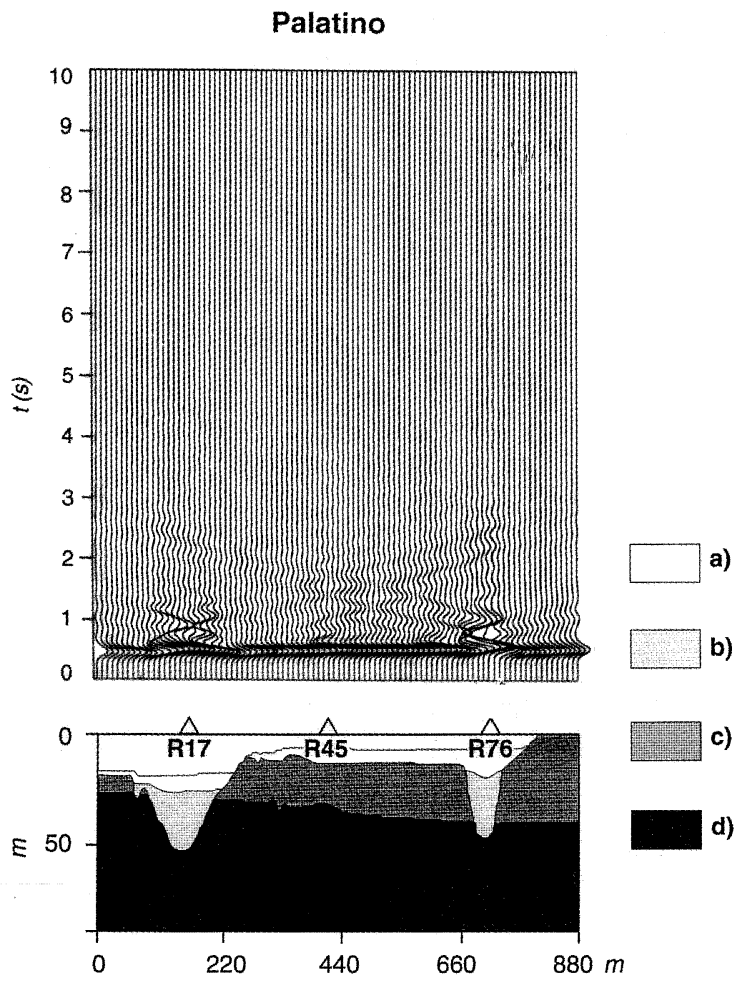

a)

Fig. 5. Two geological profiles peculiar to Rome. The Tiber river valley is the main element of the city: a large, quite regular NS structure which represents a large part of Rome's historical centre. The second one crosses the Palatino area which is characterized by the presence of close smaller-size incisions filled with unconsolidated sediments that create a single element of surface continuity with an extended soft-sediment body having extremely variable thickness. Symbols (a), (b), (c) and (d) are the same used in table IV to characterize the subsurface materials. Based on the 2-D models including topographic variations and heterogeneities of elastic and anelastic parameters, the transient response has been numerically computed using a finite-difference technique. Synthetic seismograms are the pseudoimpulse responses to a vertically incident plane $S H$ wave given by a Gabor function (see eq. 3.3). In spite of the relatively low impedance contrast and low values of $Q$, the presence of both diffracted waves at the topographic irregularities and locally generated surface waves in the soft upper layers is quite evident. Synthetic seismograms from receivers R11, R38, R73 of the Tiber valley profile, and R17, R45, R76 of the Palatino profile show the largest complexity of motion.

where $\omega_{P}=2 \pi f_{P}$ and $t_{S}=\frac{0.45 \gamma}{f_{P}}$.

The values $\gamma=0.24, \psi=\frac{\pi}{2}$, and $f_{P}=0.45 \mathrm{~Hz}$ were used in our modelling. The grid size was chosen for each profile to allow a frequency range of validity up to $8 \mathrm{~Hz}$. Given the epicentral distance of $100 \mathrm{~km}$, in our simulations we assumed a vertical incidence. Figure 5 shows the results obtained for the selected profiles. In the first profile, which is relatively simple, the topographic irregularities at the left hand side produce significant diffraction effects and an extremely complex pattern of motion, with a significant degree of asymmetry of waves at the two edges of the valley. In addition to the 
Assessment of potential strong ground motions in the city of Rome

Table IV. Elastic and anelastic parameters used for the near-surface propagation modelling.

\begin{tabular}{ccccc}
\hline \hline & Geological unit & $\begin{array}{c}\text { Density } \\
\left(\mathrm{g} / \mathrm{cm}^{3}\right)\end{array}$ & $\begin{array}{c}\text { Shear-velocity } \\
(\mathrm{m} / \mathrm{s})\end{array}$ & Quality factor \\
\hline $\mathrm{a}$ & Fill deposits & 1.95 & 150 & 5 \\
$\mathrm{~b}$ & Holocene alluvium & 1.95 & 300 & 10 \\
$\mathrm{c}$ & $\begin{array}{l}\text { Volcanic deposits } \\
\text { and Pleistocene sediments }\end{array}$ & 2.0 & 400 & 20 \\
$\mathrm{~d}$ & Pliocene clays & 2.1 & 600 & 50 \\
\hline
\end{tabular}

topographic effect of the hill on the left, the other important feature emerging from the numerical modelling is, within the valley, the propagation of the surface waves generated through mode conversion at the PlioceneHolocene discontinuity.

The modelling of the second profile (Palatino) was more interesting. As we expected, larger horizontal motions were observed in correspondence with the two incisions, but we also notice a significant level of motion in the central part of the profile. Furthermore, we observed an energy flow between the central area and the deep sediment-filled incision located on the right hand side, presumably along the man-made shallow landfill. The details of the transient-response along the Palatino profile show that the property of focusing energy on some specific sites is due to the concomitant curvature variation of the airsoil and landfill-alluvium discontinuities (the latter is concave, the former is convex). Looking at the synthetic seismograms of both the profiles of fig. 5, we notice that the response of Holocene sediments and man-made landfills is characterized by a significant magnification of both amplitudes and durations: the higher the degree of the structure irregularities, the larger the complexity of motion at the surface.

In order to quantify the largest spectral amplifications, we computed the spectral ratios at those receivers where the complexity of synthetic seismograms was higher. In fig. 6a,b the spectral amplification at three receivers of each profile is shown. Spectral ratios were computed from the Fourier amplitude spectrum of synthetic seismograms divided by the amplitude spectrum of the wavelet used as the bedrock input in the numerical modelling. These spectral ratios are divided by 2 to account for the free surface effect. They provide an estimate of the near-surface amplification in situations characteristic of the city of Rome. Figure 6a quantifies the topographic amplification of the hill (receiver R11), the 2-D resonance in the middle of a 2-km large valley (R38), and the effect of the sharp HolocenePliocene discontinuity at the right edge of the same valley (R73). Figure $6 \mathrm{~b}$ shows the $2-\mathrm{D}$ resonances of two smaller valleys (receivers R17 and R76), and quantifies the focusing effect produced by the upper-layer curvature variation near to R45. We note that the maximum ground motion amplification can be as large as a factor of 4 or more in particular frequency bands: e.g. from 6 to $7 \mathrm{~Hz}$ for the topographic effect (R11), and around $2 \mathrm{~Hz}$ for the 2-D resonances of a small valley (R76). An amplification by a factor of 3 is characteristic of the central part of the Tiber river valley, with a narrow-band spectral peak around $1 \mathrm{~Hz}$; while the edge of this valley shows a slightly lower amplification involving a broader frequency band (R73).

\subsection{Computation of the expected horizontal ground motion along 2-D profiles in the urban area}

Starting from the bedrock accelerograms $a_{B}(t)$, we can now compute the horizontal 

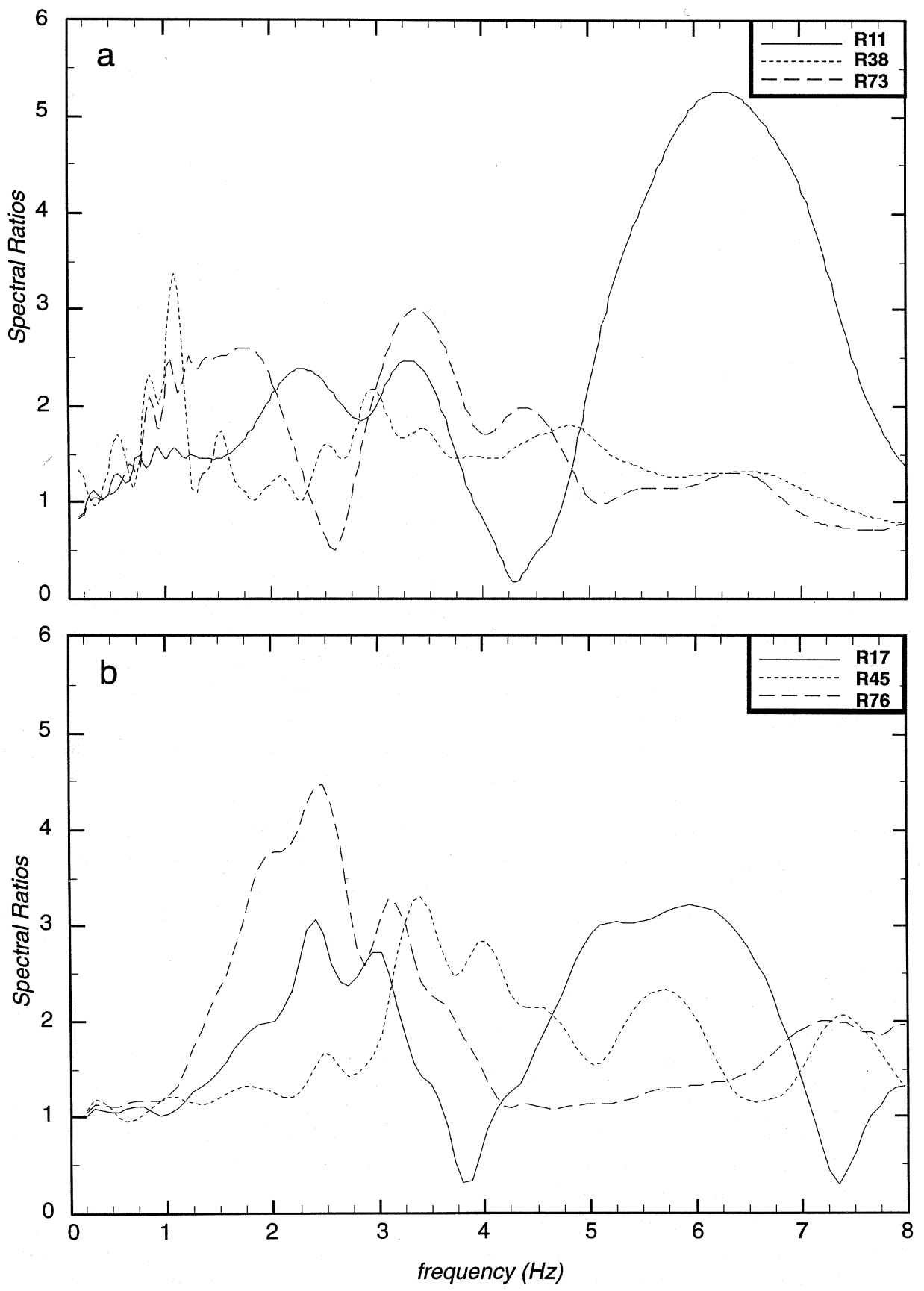

Fig. 6a,b. Amplification of ground motion as estimated by means of the spectral ratios between synthetic seismograms at the surface and the wavelet incident to the top of the bedrock. Seismograms were selected as those characterized by the largest complexity on the two profiles of fig. 5 . 
ground accelerations $a(t)$ along the profiles by means of the convolution

$$
a(t)=a_{B}(t) * h(t)
$$

where $h(t)$ is defined as the transfer function describing the propagation of $S H$ waves from the top of the bedrock to the surface, at the receiver location where the synthetic seismogram $s(t)$ was computed as the output to the bedrock input given by the Gabor function $g(t)$

$$
s(t)=g(t) * h(t) .
$$

Based on (3.4) and (3.5), the operation of convolution can be therefore written in the frequency domain as

$$
A(\omega)=A_{B}(\omega) \cdot \frac{S(\omega)}{G(\omega)}
$$

where the capital symbols denote the Fourier transform of $a(t), a_{B}(t), s(t)$ and $g(t)$, respectively. The inverse Fourier transform of $A(\omega)$ yields the time histories of the ground acceleration along the selected profiles.

Let we consider one of the individual accelerograms $a_{B}(t)$ computed as the bedrock input for a magnitude 7 earthquake at a distance of $100 \mathrm{~km}$ from Rome. Applying (3.6) and the inverse Fourier transformation we obtain one individual simulation of ground acceleration for each receiver along the two arrays of profiles (a) and (b). Some examples of time histories of ground acceleration and velocity simulated with the assumption of pure $S H$-wave propagation are shown in fig. 7a-d. Velocities are obtained by integrating accelerations. Figure 7a-d stresses the occurrence of large variations between firm and soft sites, mainly for the acceleration time histories.

To average the fluctuations of the individual simulations, 25 sets of surface accelerograms were computed using the different bedrock accelerograms of the ensemble. In addition to peak ground acceleration and velocity, the inte- gral quantitites

and

$$
I_{A}=\int_{0}^{T} a^{2}(t) d t
$$

$$
I_{V}=\int_{0}^{T} v^{2}(t) d t
$$

were calculated from the convolved time histories, and averaged over the ensemble of the 25 simulations. $T$ is the total duration of motion. $I_{A}$ and $I_{V}$ are proportional to the Arias intensity (Arias, 1970) and to the flux of seismic energy (Boatwright, 1980), respectively. Figure 8 shows the average behaviour of $a_{P}, I_{A}, v_{P}$, and $I_{V}$ along the two profiles. For all of them, the statistical uncertainties represent the interval of \pm 1 standard deviation. In general, the behaviour of $I_{A}$ and $I_{V}$ follows $a_{P}$ and $v_{P}$, respectively. But the largest amplification of $a_{P}$ and $I_{A}$ does not necessarily occur at the same sites where $v_{P}$ and $I_{V}$ reach their highest values, depending on the frequency band of amplification: accelerations are more sensitive to highfrequency amplifications, velocities to lowerfrequency ones.

The sharp variations of all the above mentioned parameters along the profiles testify to a high sensitivity of ground motion to the details of soil stratigraphy and topography. As stressed by Faccioli (1992), in the recent literature many evidences emerge concerning the amplification of both peak ground acceleration and velocity as a function of thickness and velocity of the upper soft layers. In this work, values as large as 67 gals and $7 \mathrm{~cm} / \mathrm{s}$ are found for $a_{P}$ and $v_{P}$, respectively, against an estimate of 26 gals and $4.6 \mathrm{~cm} / \mathrm{s}$, respectively, for a bedrock having a shear-wave velocity equal to $600 \mathrm{~m} / \mathrm{s}$. Note that these two peak values at the bedrock are different than those deriving from relation (3.2): for sake of comparison the bedrock time histories had to be low-pass filtered at $8 \mathrm{~Hz}$, that was the maximum frequency allowed by the grid size in our computations, and this reduced $a_{P}$ from 30 to 26 gals, and $v_{P}$ from 4.8 to $4.6 \mathrm{~cm} / \mathrm{s}$. Consequently, along the selected profiles peak ground acceleration shows a maximum amplification of 2.6 , while the maximum amplification of peak ground ve- 
Tiber Valley

Palatino

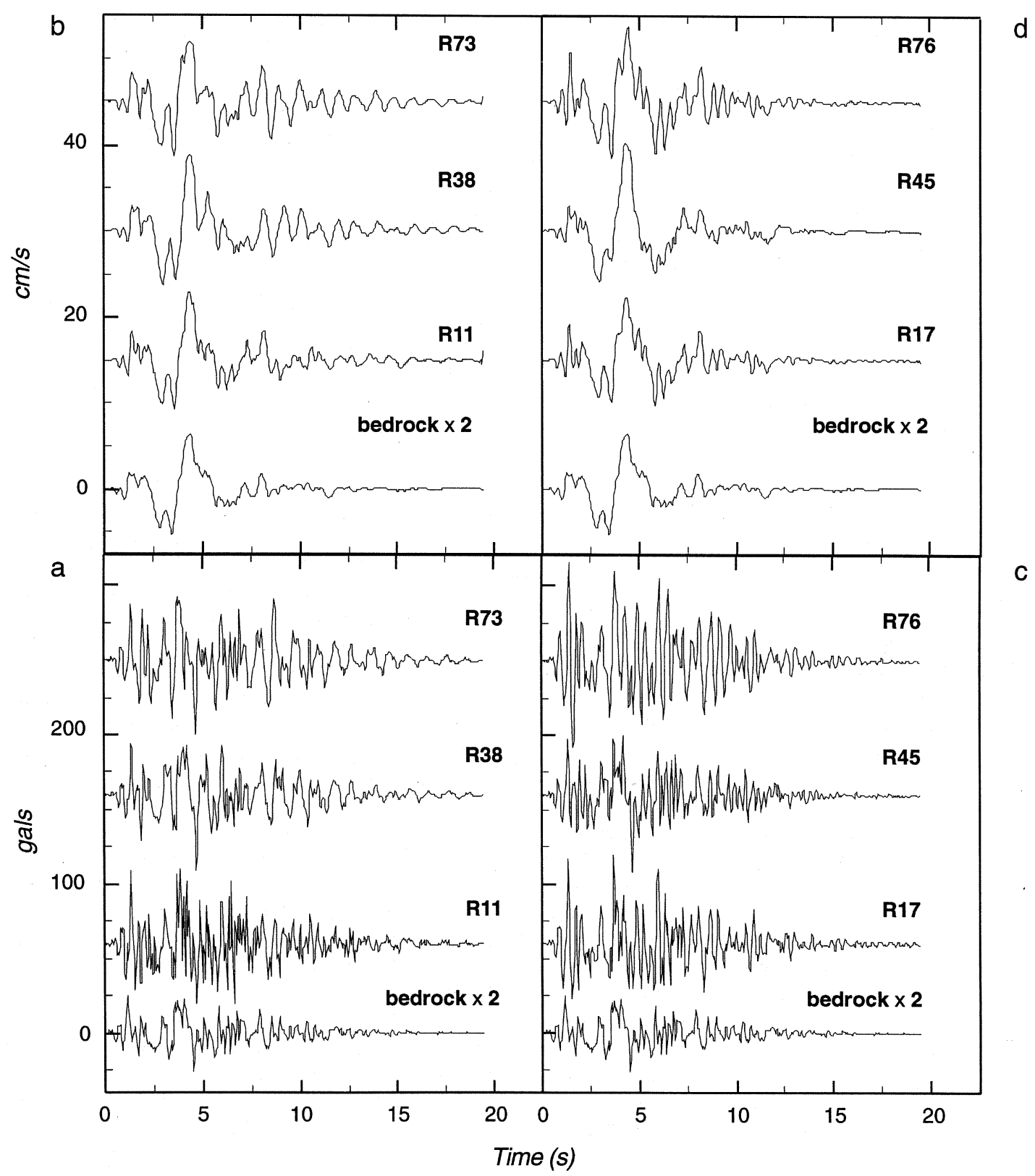

Fig. 7a-d. Simulation of ground motion derived from convolution (3.5) for three receivers along the Tiber river valley (time histories in (a) are accelerations, in (b) velocities) and the Palatino profile (time histories in (c) are accelerations, in (d) velocities). To better focus the effect of the near-surface propagation, the bedrock input has been multiplied by 2 to account for the free surface effect. 

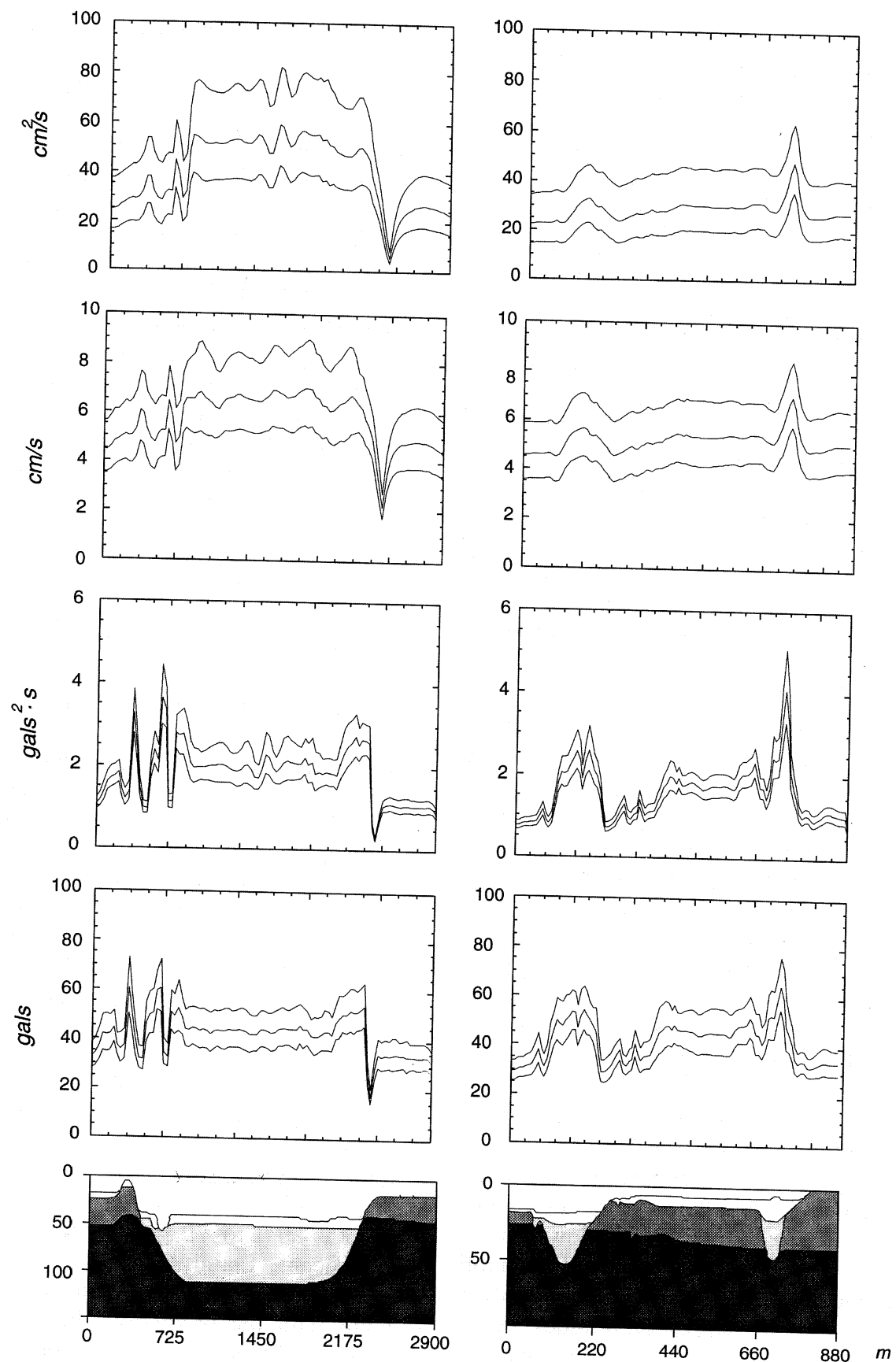

Fig. 8. From bottom to top: behaviour of $a_{P}, I_{A}, v_{P}$, and $I_{V}$ as a function of topography and near-surface geologic materials along the selected profiles. The three curves represent the mean value \pm 1 s.d. resulting from the operation of average over the ensemble of 25 simulations. 
locity is 1.5 . These maximum amplification factors of 2.6 and 1.5 appear to be larger than those estimated by Sabetta and Pugliese (1987) using the entire data set of the Italian strong motions (1.48 and 1.36, respectively). However, it has to be noted that the level corresponding to the Sabetta and Pugliese's peak amplification factors well fit, on the average, the variability of $a_{P}$ and $v_{P}$ in fig. 8 .

Some 2-D local effects seem to be responsible for the largest amplifications of ground motion: the most evident are: 1) the sharp variations of the motion parameters in correspondence of the hill and other topographic irregularities at the left hand side of Tiber Valley profile; 2) the edge effect at sediment sites near to the sharp Pliocene-Holocene discontinuity at the right hand side of the same profile, and 3) the 2-D resonances of the sediment filled valleys in the Palatino profile. All these amplification phenomena were object of investigation in the recent literature (e.g. see Sánchez-Sesma, 1985; Bard and Bouchon, 1985; Moczo and Bard, 1993; Moczo et al., 1994): in this paper the size of those effects have been quantified for a realistic ground motion produced in the city of Rome by a magnitude 7 earthquake at a distance of $100 \mathrm{~km}$.

One more parameter relevant to the earthquake engineering purposes has been taken into account: the response spectrum. Some examples are shown in fig. 9: 5\% damped pseudovelocity response spectra reach values as large as $15-20 \mathrm{~cm} / \mathrm{s}$ for the most amplified receivers, at frequencies varying from 1 to $3 \mathrm{~Hz}$. In order to visualize the average behaviour of this parameter as a function of frequency and spatial location over the profiles, in fig. 10a,b spectral amplitudes were averaged over the ensemble of the 25 simulations and represented by means of a colour scale. Yellow denotes amplitudes higher than $10 \mathrm{~cm} / \mathrm{s}$, pink amplitudes ranging between 8 to $10 \mathrm{~cm} / \mathrm{s}$, roughly. It is confirmed that the largest amplitudes are coincident with 2-D local effects, but also the large flat valley of Tiber river produce a highamplitude narrow-band spectral peak on pseudovelocity response spectra (see figs. 9 and 10a,b).

\section{Discussion of results and conclusions}

Several methods to perform numerical simulations of the potential shaking are currently in use, but their reliability and accuracy have to be rigorously tested. As far as the city of Rome is concerned, Fäh et al. (1993) used the mode summation technique with a 2-D scheme of layered lithosphere to simulate the incoming wavefield to the bedrock of Rome generated by a $M_{L}=6.8$ earthquake roughly $85 \mathrm{~km}$ east of the city, and a finite-difference technique to model the local geology effects. To avoid too simplified crustal models unsuitable for a very heterogeneous region, in this paper we modelled source properties and long-path propagation through a stochastic technique (Boore, 1983) based on the observed spectra of ground motion in the region (Rovelli et al., 1988), and the effects of the near-surface geology in the city were simulated by means of a finite-difference technique for the transverse component of motion. The technique was applied to 2-D models including topographic variations. Finally, we studied the variation of many of the parameters used for earthquake engineering purposes $\left(a_{P}, v_{P}, I_{A}, I_{V}, 5 \%\right.$ damped response spectra) as a function of different geological and topographic conditions.

As strong-motion data are not available for the city of Rome, the most appropriate way to test the reliability of the different methods is to compare the ground motion derived from simulations with observations available in similar conditions. Figure 11a,b is redrawn from the paper by Sabetta and Pugliese (1987) who computed the curves of attenuation of peak ground acceleration and velocity for the Italian strong-motion data set. The values of $a_{P}$ obtained from our simulations are ranging from 30 gals (firm sites, with a shear-wave velocity of $600 \mathrm{~m} / \mathrm{s}$ ) to 70 gals (soft sites showing a significant, mainly 2-D local amplification): this variability interval is in very good agreement with the predictions based on the relationships by Sabetta and Pugliese (1987). Our values of $v_{P}$ are also in substantial agreement with the Sabetta and Pugliese's ones, slightly overestimating their predictions. Fäh et al. (1993) did not compute time histories of 

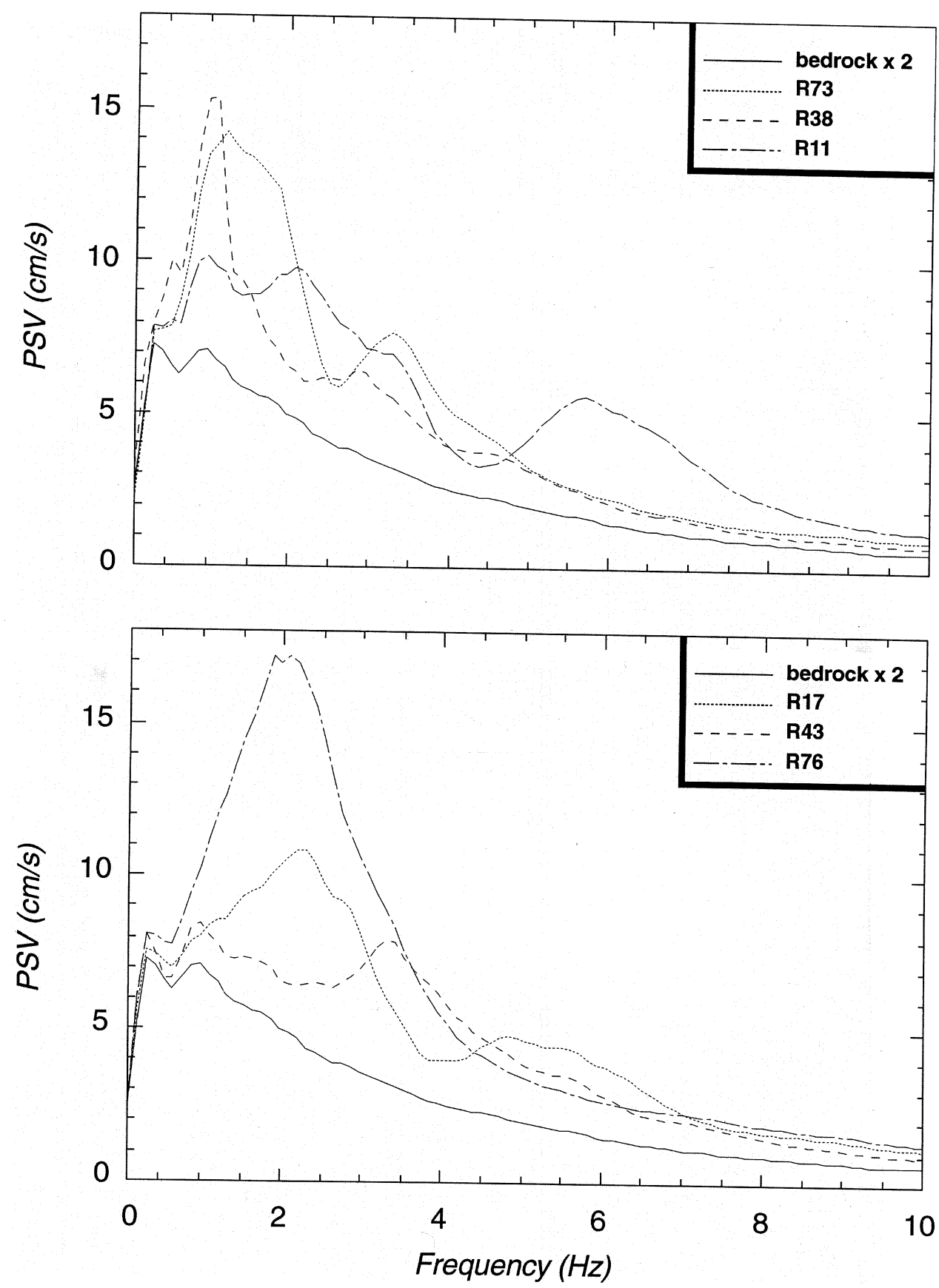

Fig. 9. Examples of 5\% damped pseudovelocity response spectra resulting for sites with large amplification. For sake of comparison, the bedrock behaviour is also shown. All curves were obtained as the average over the ensemble of 25 simulations. 


\section{Tiber Valley}

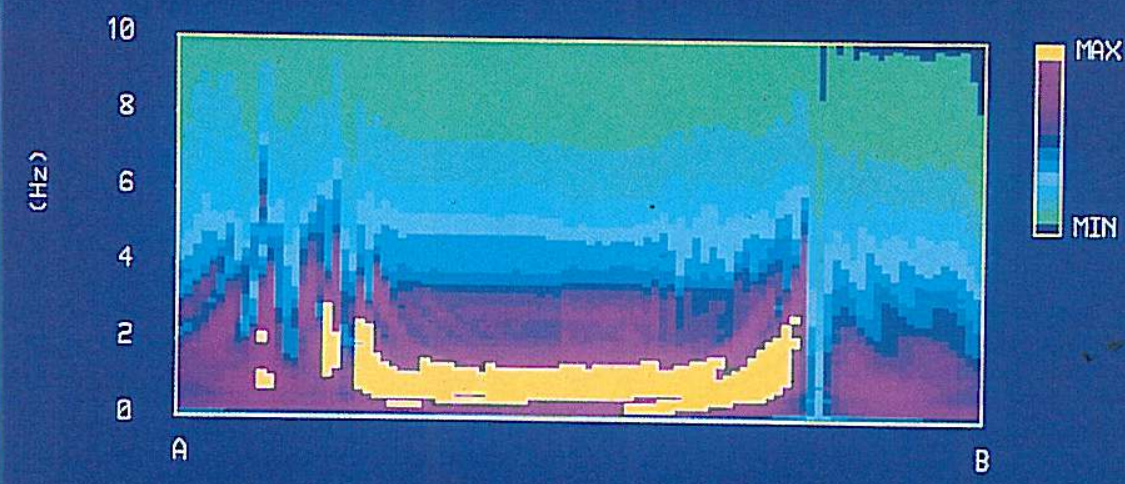

(a)

\section{Palat ino}

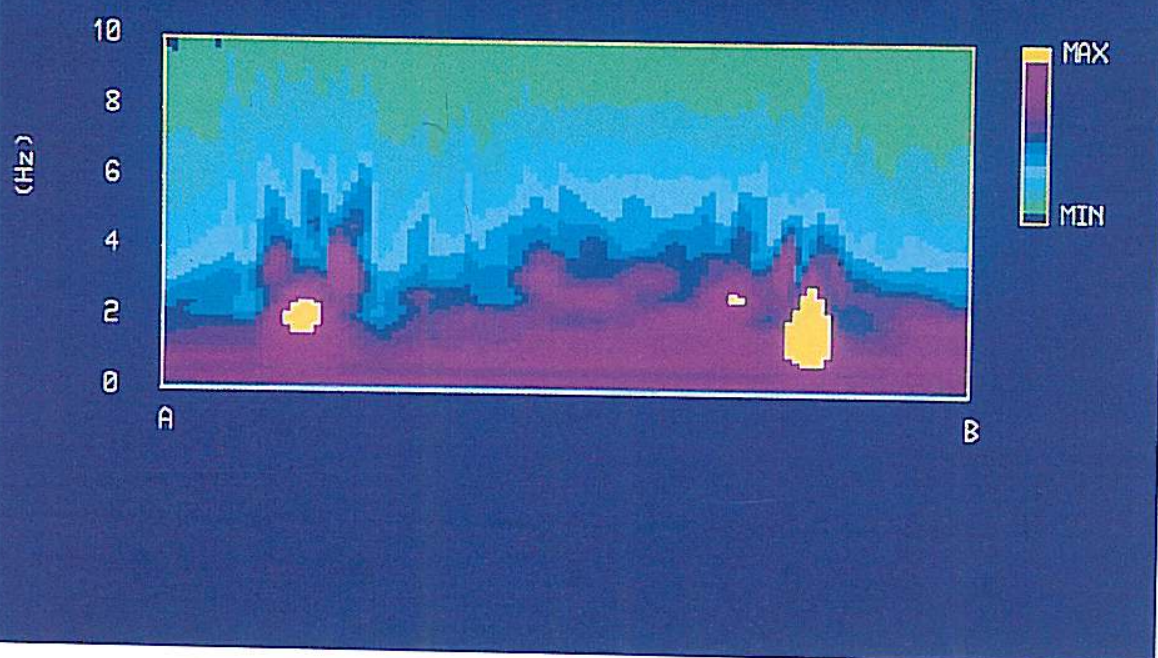

Fïg. 10a,b. Behaviour of the average $5 \%$ damped pseudovelocity response spectra as a function of frequency and spatial location along (a) the Tiber river valley and (b) the Palatino profile. A and B are the extreme sites of the two profiles. The colour scale visualizes the amplitude variations of response spectra: yellow means spectral values higher than $10 \mathrm{~cm} / \mathrm{s}$, pink values ranging from 8 to $10 \mathrm{~cm} / \mathrm{s}$, roughly. 

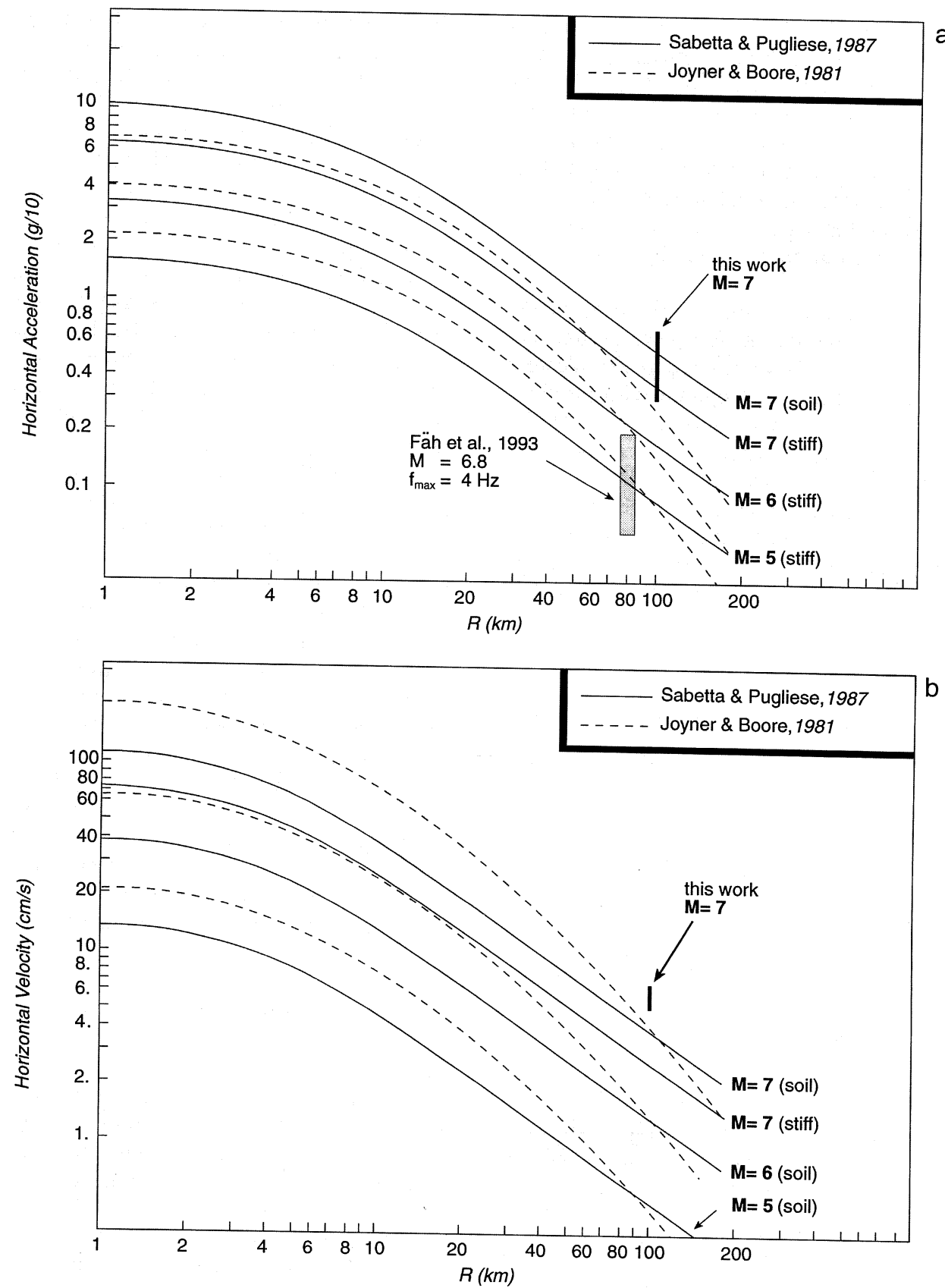

Fig. 11a,b. Range of variability (vertical bar) of (a) peak ground acceleration and (b) peak ground velocity predicted in this work for the city of Rome in the case of a large earthquake in the Apennines, compared with the regressions by Sabetta and Pugliese (1987). The results of the simulations by Fäh et al. (1993) are also shown (grey rectangle in (a)). 
ground velocity, but their predictions of ground accelerations appear to be significantly underestimated suggesting that simulation methods based on a deterministic propagation through flat layers are not adequate for earthquake engineering applications due to the oversimplification of the mathematical model which does not represent the reality, and for the lack of physical information in the high-frequency band.

Recently, Boore et al. (1993) reevaluated the curves of attenuation for peak ground acceleration and response spectra from Western North American data. Compared with previous evaluations (Joyner and Boore, 1981, 1988), the addition of accelerograms from the 1989 Loma Prieta, 1992 Petrolia, and 1992 Landers earthquakes made the data set collected by Boore et al. (1993) extremely rich and suitable to predict ground motion parameters at large distances $(R \geq 100 \mathrm{~km})$ for magnitude $\approx 7$, a

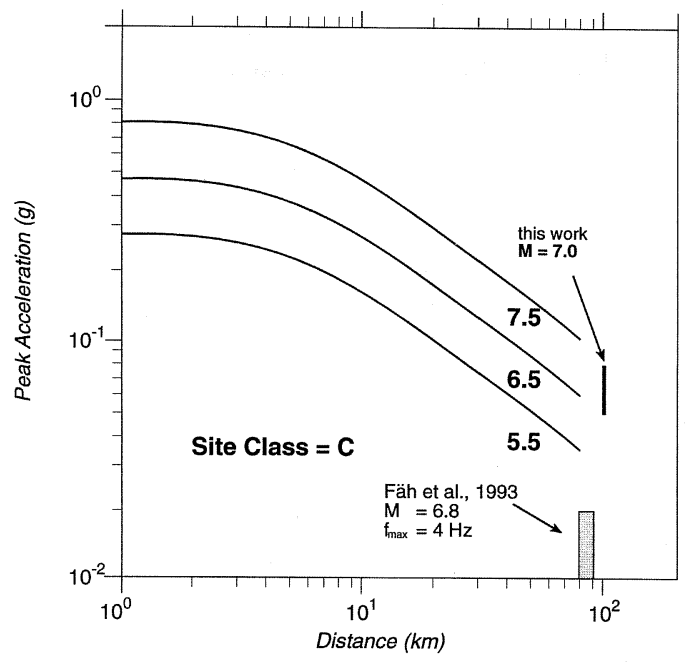

Fig. 12. Range of variability of peak ground acceleration (vertical bar) predicted in this work for softsites (class C of the Boore et al., 1993, classification) in the city of Rome, as compared with the regressions resulting from the Western North American data (redrawn from Boore et al., 1993). The results of the simulations by Fäh et al. (1993) are also shown (grey rectangle). situation that is not so well statistically constrained using the Italian data set. Moreover, in their new site geology classification, class $\mathrm{C}$ includes sites with upper-layer shear-wave velocities between 180 and $360 \mathrm{~m} / \mathrm{s}$, a range of variability extremely suitable to fit the surface geology of Rome (see table IV). The estimates of $a_{P}$ and 5\% damped response spectra obtained numerically for site class $\mathrm{C}$ on the profiles of fig. 5 are then compared with the values predicted by the regressions by Boore et al. (1993). Figures 12 and 13 visualize this comparison. Again, the values predicted by Fäh et al. (1993) underestimate observations significantly (fig. 12). On the contrary, following our approach a good agreement is obtained between predictions and observed data, including pseudovelocity response spectra (fig. 13).

In conclusion, our results confirm that stochastic simulations can play an important role in earthquake engineering applications. They seem to be more adequate than the deterministic modelling. Their best performance is to provide synthetic accelerograms for sites where instrumental data were never recorded, but source properties and attenuation laws were estimated from instrumental data available for the area at local and regional scale. This is the case of the city of Rome, where strong-motion data have not been recorded so far but the local geology is sufficiently well known and regional properties of ground motion were object of previous papers.

\section{Acknowledgements}

Some years ago Renato Funiciello promoted a project to collect all the dispersed data concerning the surface geology and stratigraphy of Rome: now the data bank has been computerized and allows us to performe computations of the seismic response of Rome based on real $\log$ data. Enzo Boschi's interest was decisive for the developement of this research. In addition to internal research funds by ING, we benefited from a partial funding by the Italian Consiglio Nazionale delle Ricerche, under a grant of the Progetto Strategico Beni Culturali. We gratefully acknowledge the cooperation of 


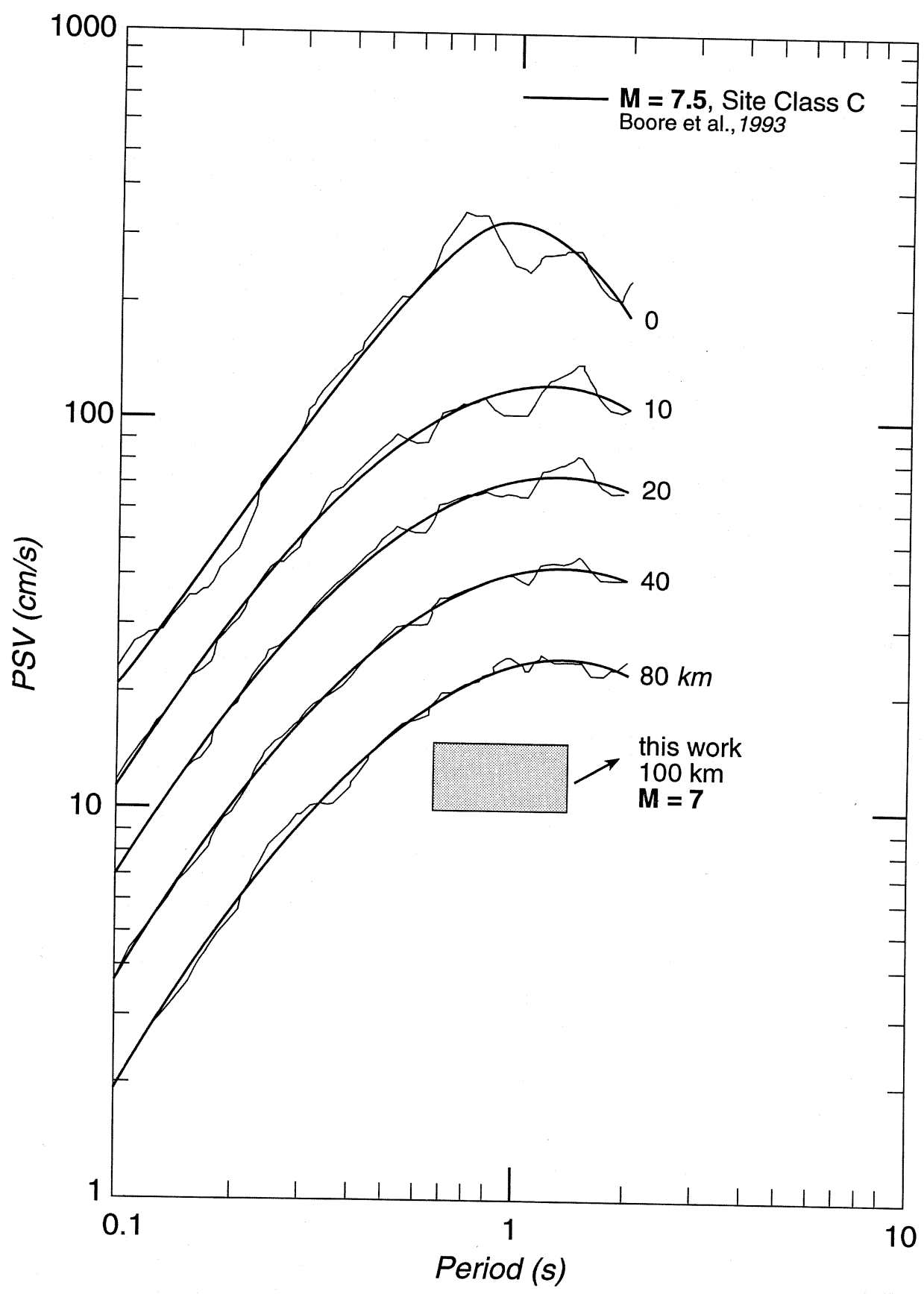

Fig. 13. Range of variability of the average 5\% damped pseudovelocity response spectra (grey rectangle) predicted in this work for soft sites (class C of the Boore et al., 1993, classification) in the city of Rome, as compared with the regressions resulting from the Western North American data (redrawn from Boore et al., 
all the local Public Authorities (Comune di Roma, Provincia di Roma, Regione Lazio): special thanks are due to Carmine Lanzara for the space devoted to seismic risk issues in the framework of the Commissione per i Rischi Ambientali nel Centro Storico di Roma, and to Renato Caccavelli and Maurizio Alimonti of the Assessorato per la Protezione Civile della Regione Lazio. A financial contribution from the Regione Lazio is also acknowledged.

We want to thank Massimo Cocco, Fabio Sabetta, Diego Molin, Peter Moczo, Raniero Berardi, and Renato Funiciello for valuable comments and helpful discussions, and Ilaria Leschiutta for compiling the geologic crosssections used in this study. The manuscript was significantly improved by a review from Dave Boore. Appreciation is expressed for the Daniela Riposati's patience in constructing the figures.

\section{REFERENCES}

Alfonsi, L., R. Funiciello, M. Mattei, O. Girotti, A. Maiorani, M. Preite Martinez, C. Trudu and B. Turi (1991): Structural and geochemical features of the Sabina strike-slip fault (Central Appenines). Boll. Soc. Geol. It., 110, 217-230.

Amato, A., C. Chiarabba, M. Cocco, M. Di Bona and G. SelvagGi (1994): The 1989-1990 seismic swarm in the Alban Hills volcanic area, Central Italy, J. Vol. Geotherm. Res., 61, 225-237.

Ambrosini, S., S. Castenetto, F. Cevolan, E. Di Loreto, R. Funiciello, L. Liperi and D. Molin (1987): Risposta sismica dell'area urbana di Roma in occasione del terremoto del Fucino del 13-1-1915, Mem. Soc. Geol. It., 35, 445-452 (in Italian).

Anderson, J.G. and S.E. Hough (1984): A model for the shape of the Fourier amplitude spectrum of acceleration at high frequencies, Bull. Seismol. Soc. Am., 74, 1969-1993.

ArIAS, A. (1970): A measure of earthquake intensity, in Seismic Design for Nuclear Power Plants, edited by R. HANSEN (Cambridge, Mass.), 438-483.

BARD, P.-Y. and M. Bouchon (1985): The two-dimensional resonance of sediment-filled valleys, Bull. Seismol. Soc. Am., 75, 519-541.

Basili, A., P. Favali, G. Scalera and G. Smriglio (1987): Valutazione della pericolosità sismica in Italia centrale con particolare riguardo alla città di Roma, in VI Convegno Nazionale del GNGTS, CNR, Rome, Italy, 379393 (in Italian).

BoAtwright, J. (1980): A spectral theory for circular seismic sources: simple estimates of source dimension, dynamic stress drop and radiated energy, Bull. Seismol. Soc. Am., 70, 69-94.
Boore, D.M. (1983): Stochastic simulation of high-frequency ground motions based on seismological models of the radiated spectra, Bull. Seismol. Soc. Am., 73, $1865-1894$.

Boore, D.M. (1986): Short-period $P$ - and $S$-wave radiation from large earthquakes: implications for spectral scaling relations, Bull. Seismol. Soc. Am., 76, 43-64.

Boore, D.M., W.B. Joyner and T.E. Fumal (1993): Estimation of response spectra and peak accelerations from Western North American earthquakes: an interim report, U.S. Geol. Surv. Open-file Rept. 93-509, pp. 72.

Boschi, E., A. Caserta, C. Conti, M. Di Bona, R. Funiciello, L. Malagnini, F. Marra, G. Martines, A. RovELLI and S. SALVI (1994): Resonance of subsurface sediments: an unforeseen complication for designers of Roman columns, Bull. Seismol. Soc. Am. (in press).

Brunamonte, F., A.M. Michetti, L. Serva and E. Vittori (1991): Evidenze paleosismologiche nell'Appennino Centrale ed implicazioni neotettoniche, Studi Geologici Camerti, 2 (special issue), 265-270 (in Italian).

Carboni, M.G., R. Funiciello, M. Parotto, F. Marra, S. Salvi, A. Corazza, L. Lombardi and M. Feroci (1991): Geologia e idrogeologia del centro storico di Roma, in Progetto Strategico Roma Capitale, AA.VV., CNR, Rome, Italy (in Italian).

Chiarabba, C., L. Malagnini and A. Amato (1994): Threedimensional velocity structure and earthquake relocation in the Alban Hills Volcano, Central Italy, Bull. Seismol. Soc. Am., 84, 295-306.

Cioni, R., M.A. Laurenzi, A. Sbrana and I.M. Villa (1993): 40Ar/39Ar chronostratigraphy of the initial activity in the Sabatini volcanic complex (Italy), Boll. Soc. Geol. It., 112, 251-263.

Cocco, M. and A. Rovelli (1989): Evidence for the variation of stress drop between normal and thrust faulting earthquakes in Italy, J. Geophys. Res., 94, 93999416.

Cosentino, D. and M. Parotto (1992): La struttura a falde della Sabina (Appennino Centrale), in Studi Geologici Camerti, CROP 11, 2 (special issue), 381-397 (in Italian).

Cranswick, E., K. King, D. Carver, D. Worley, R. Williams, P. Spudich and R. Banfill (1990): Site response across downtown Santa Cruz, California, Geophys. Res. Lett., 17, 1793-1796.

Di Bona, M. and A. Rovelli (1990): Simulazione stocastica del movimento del suolo basata su un modello spettrale della radiazione sismica, Int. Rep. 522, ING, Rome (in Italian).

EMmerich, H. and M. KoRN (1987): Incorporation of attenuation into time-domain computations of seismic wave fields, Geophysics, 52, 1252-1264.

Faccenna, C. and R. Funiciello (1993): Tettonica pleistocenica tra il M. Soratte ed i Monti Cornicolani (Lazio), Il Quaternario, 6, 103-118 (in Italian).

FACCIOLI, E. (1992): Selected aspects of the characterization of seismic site effects, including some recent European contributions, in Proceedings of the International Symposium on the Effects of Surface Geology on Seismic Motion, Odawara, Japan, 65-96.

Fäh, D., C. Iodice, P. Suhaldoc and G. Panza (1993): A new method for the realistic estimation of seismic 
ground motion in megacities: the case of Rome, Earthquake Spectra, 9, 643-667.

Feroci, M., R. Funiciello, F. Marra and S. SAlvi (1990): Nuovi dati sull'assetto geologico dell'area romana, $I l$ Quaternario, 3, 141-158 (in Italian).

Funiciello, R., R. Giuliani, F. Marra and S. SAlvi (1992): Superfici strutturali plio-quaternarie al margine sudorientale del distretto vulcanico Sabatino, in Studi Geologici Camerti, CROP 11, 2 (special issue), 301-304 (in Italian).

Galadini, F., R. Gululani and P. Messina (1991): Characterization of recent deformational sequences in some areas of the Abruzzi Apennines (Central Italy): implications and problems, Il Quaternario, 4, 85-98.

Gibis J.F., D.M. Boore, W.B. Joyner and T.E. Fumal (1994): The attenuation of seismic shear waves in Quaternary alluvium in Santa Clara Valley, California, Bull. Seismol. Soc. Am., 84, 76-90.

Jongmans, D. and M. Campillo (1993): The determination of geophysical prospecting and the validity of measured $Q$ values for numerical simulations, Soil Dynamics and Earthquake Engineering, 12, 149-157.

JOYNER, W.B. and D.M. Boore (1981): Peak horizontal acceleration and velocity from strong-motion records from the 1979 Imperial Valley, California, earthquake, Bull. Seismol. Soc. Am., 71, 2011-2038.

JoYNeR, W.B. and D.M. Boore (1988): Measurement, characterization and prediction of strong ground motion, in Proceedings of Earthquake Engineering and Soil Dynamics II, GT Div/ASCE, Park City, Utah, 43-102.

Joyner, W.B. and T.E. Fumal (1984): Use of measured shear-wave velocity for predicting geologic site effects on strong ground motion, in Proceedings 8th World Conf. Earthq. Engineering, San Francisco, California, 2, 777-783.

Malagnini, L., R.B. Herrmann, S. Opice, G. Biella and R. DE Franco (1994): Rayleigh waves in Quaternary alluvium from explosive sources: determination of shearwave velocity and $Q$ structure, Bull. Seismol. Soc. Am. (in press).

Marra, F. (1994): Stratigrafia e assetto geologico-strutturale dell'area romana tra il Tevere e il Rio Galeria, Geologica Romana, 29, 515-535 (in Italian).

Marra, F., M.G. Carboni, L. Di Bella, C. Faccenna, R. FuNICIEllo and C. Rosa (1994a): Il substrato plio-pleistocenico nell'area romana, Boll. Soc. Geol. It. (in Italian).

Marra, F., C. Rosa, D. De Rita and R. Funiciello (1994b): Stratigraphic and tectonic features of the Middle Pleistocene sedimentary and volcanic deposits in the area of Rome (Italy), Quaternary International (in press).

Mitchell, A.R. and D.F. GRIFFITH (1980): The finite difference method in partial differential equations (John Wiley \& Sons Ltd., New York).

Moczo, P. and P.-Y. BARD (1993): Wave diffraction, amplification and differential motion near strong lateral discontinuities, Bull. Seismol. Soc. Am., 83, 85-106.

Moczo, P., A. Rovelli, P. Labàk and L. Malagnini (1994): Seismic response of the geologic structure underlying the Roman Colosseum and a 2-D resonance of a sediment valley, Annali di Geofisica (in press).

Molin, D. and E. Guidoboni (1989): Effetto fonti, effetto monumenti a Roma: i terremoti dall'antichità a oggi, in I Terremoti Prima del Mille in Italia e nell'Area Mediterranea, edited by E. Guidoboni (SGA, Bologna, Italy), 194-223 (in Italian).

Pantosti, D., G. D’Addezio, F.R. Cinti, D.P. Schwartz and J.C. Hamilton (1992): Evidence for a prehistoric surface faulting earthquake on the Ovindoli-Pezza fault, Central Italy, EOS Trans. Am. Geophys. U., 73, 353 (abstract).

Pugliese, A. and F. Sabetta (1989): Stima di spettri di risposta da registrazioni di forti terremoti italiani, Ingegneria Sismica, 6, 3-14 (in Italian).

Rovelli, A., O. Bonamassa, M. Cocco, M. Di Bona and S. MAZZA (1988): Scaling laws and spectral parameters of the ground motion in active extensional areas in Italy, Bull. Seismol. Soc. Am., 78, 530-560.

Sabetta, F. and A. Pugliese (1987): Attenuation of peak horizontal acceleration and velocity from Italian strong-motion records, Bull. Seismol. Soc. Am., 77, 1491-1513.

Salvi, S., E. Boschi, M. Di Bona, R. Funiciello, L. Malagnini, F. Marra and A. Rovelli (1991): Subsurface geology and variations of seismic response in the city of Rome, in Fourth International Conference on Seismic Zonation, Stanford, California, 115-122.

SÁncheZ-Sesma, F. (1985): Diffraction of elastic $S H$-waves by wedges, Bull. Seismol. Soc. Am., 75, 1435-1446.

Serva, L., A.M. Blumetti and A.M. Michetti (1986): Gli effetti sul terreno del terremoto del Fucino (13 gennaio 1915); tentativo di interpretazione della evoluzione tettonica recente di alcune strutture, Mem. Soc. Geol. It., 35, 893-907 (in Italian).

Singh, S.K., E. Mena and R. Castro (1988): Some aspect of source characteristics of the 19 September $1985 \mathrm{Mi}-$ choacan earthquake and ground motion amplification in and near Mexico City from strong motion data, Bull. Seismol. Soc. Am., 78, 451-477.

Valensise, G., D. Pantosti, G. D'Addezio, F.R. Cinti and L. Cucci (1993): L'identificazione e la caratterizzazione di faglie sismogenetiche nell'Appennino Centro-Meridionale e nell'Arco Calabro: nuovi risultati e ipotesi interpretative, in XII Convegno Nazionale del GNGTS, CNR, Rome, Italy (in press).

Valensise, G., D. Pantosti and E. Boschi (1994): Matching history with geology: a novel approach to Italian seismic hazard, Nature (submitted).

WARD, S.N. and G. VALENSISE (1989): Fault parameters and slip distribution of the 1915, Avezzano, Italy, earthquake derived from geodetic observations, Bull. Seismol. Soc. Am., 79, 690-710.

WigGer, J. (1984): Die Krustenstruktur des NordAppennines und angereurender Gebeite mit besonder Bernecksichtigung der geotermischen Anomalie der Toskana, Berl. Geowiss. Abh. (Reihess Heft), 9, 1-87 (in German). 